\title{
Impact of inducible nitric oxide synthase (iNOS) expression on triple negative breast cancer outcome and activation of EGFR and ERK signaling pathways
}

\author{
Pablo Garrido ${ }^{1,7}$, Aliaa Shalaby ${ }^{1}$, Elaine M. Walsh ${ }^{1}$, Nessa Keane ${ }^{1}$, Mark Webber ${ }^{1}$, \\ Maccon M. Keane ${ }^{2}$, Francis J. Sullivan ${ }^{3}$, Michael J. Kerin ${ }^{4}$, Grace Callagy ${ }^{1}$, Aideen \\ E. Ryan ${ }^{5,6}$ and Sharon A. Glynn ${ }^{1,3,7}$ \\ ${ }^{1}$ Discipline of Pathology, Lambe Institute for Translational Research, School of Medicine, National University of Ireland \\ Galway, Galway, Republic of Ireland \\ ${ }^{2}$ Medical Oncology, Galway University Hospital, Galway, Republic of Ireland \\ ${ }^{3}$ Prostate Cancer Institute, National University of Ireland Galway, Galway, Republic of Ireland \\ ${ }^{4}$ Discipline of Surgery, Lambe Institute for Translational Research, School of Medicine, National University of Ireland Galway, \\ Galway, Republic of Ireland \\ ${ }^{5}$ Discipline of Pharmacology and Therapeutics, Lambe Institute for Translational Research, School of Medicine, National \\ University of Ireland Galway, Galway, Republic of Ireland \\ ${ }^{6}$ Regenerative Medicine Institute (REMEDI), Biomedical Sciences, National University of Ireland Galway, Galway, Republic of \\ Ireland \\ ${ }^{7}$ Apoptosis Research Centre, National University of Ireland Galway, Galway, Republic of Ireland \\ Correspondence to: Sharon A. Glynn, email: sharon.glynn@nuigalway.ie \\ Keywords: triple negative breast cancer, EGFR, inflammation, metastasis, nitric oxide \\ Received: January 17, $2017 \quad$ Accepted: July 03, 2017 Published: July 26, 2017 \\ Copyright: Garrido et al. This is an open-access article distributed under the terms of the Creative Commons Attribution License \\ 3.0 (CC BY 3.0), which permits unrestricted use, distribution, and reproduction in any medium, provided the original author and \\ source are credited.
}

\section{ABSTRACT}

Inflammation is implicated in triple negative breast cancer (TNBC) progression. TNBC carries a worse prognosis than other breast cancer subtypes, and with the clinical and molecular heterogeneity of TNBC, there is a lack of effective therapeutic targets available. Identification of molecular targets for TNBC subtypes is crucial towards personalized patient stratification. Inducible nitric oxide synthase (iNOS) has been shown to induce p53 mutation accumulation, basal-like gene signature enrichment and transactivation of the epidermal growth factor receptor (EGFR) via s-nitrosylation. Herein we report that iNOS is associated with disease recurrence, distant metastasis and decreased breast cancer specific survival in 209 cases of TNBC. Employing TNBC cell lines representing normal basal breast, and basal-like 1 and basal-like 2 tumors, we demonstrate that nitric oxide (NO) induces EGFR-dependent ERK phosphorylation in basal-like TNBC cell lines. Moreover NO mediated cell migration and cell invasion was found to be dependent on EGFR and ERK activation particularly in basal-like 2 TBNC cells. This occurred in conjunction with NF-KB activation and increased secretion of pro-inflammatory cytokines IL-8, IL-1 $\beta$ and TNF-a. This provides substantial evidence for EGFR as a therapeutic target to be taken into consideration in the treatment of a specific subset of basal-like TNBC overexpressing iNOS.

\section{INTRODUCTION}

Triple negative breast cancers (TNBC) account for $15-20 \%$ of breast cancers and are characterized by a lack of estrogen receptors (ER), progesterone receptors (PR) or HER2 receptors $[1,2]$. TNBC patients have limited treatment options, exhibit earlier recurrence and poorer prognosis compared to non-TNBC patients [3]. TNBC is 
in reality a highly diverse group of cancers and despite the efforts of several groups in identification of phenotype/ subtype specific expression patterns and gene signatureclassification models, controversy remains regarding their subtyping [4, 5]. Nevertheless, most of the classifications agree in subdividing them into at least basal-like, mesenchymal, and luminal androgen receptor (LAR). Basal-like tumors constitute over $70 \%$ of the TNBC [4], and are further subdivided into basal-like 1 (BL1) and basal-like 2 (BL2). BL1 tumors are mainly driven by BRCA and cell cycle/cell division pathways, while the BL2 are mainly driven receptor tyrosine kinases (RTKs) $[4,6]$. Improved stratification of this heterogeneous group is crucial to find new therapeutic strategies for TNBC.

Nitric oxide (NO) is a small biomolecule which exerts multiple effects on tumor biology [7, 8]. NO regulates a wide range of intracellular events through s-nitrosylation and regulation cell redox $[9,10]$. The biological effects of NO are dose and temporal dependent with the ability to either inhibit or stimulate cell proliferation, migration and apoptosis [7, 11, 12]. Inducible nitric oxide synthase (iNOS) is a proinflammatory enzyme implicated in chronic inflammation and wound healing which synthesizes NO [13]. We previously demonstrated that iNOS is associated with poor survival in ER-negative breast cancer patients and enhanced expression of basal-like gene signatures [14]. Additionally we demonstrated that iNOS was associated with epidermal growth factor receptor (EGFR) activation [14] via s-nitrosylation [9]. This led us to hypothesize that iNOS may play a role in the progression of basallike TNBC via enhanced activation of EGFR signaling. This study aims to identify the degree to which iNOS pays a role in TNBC progression and patient survival, in addition to identifying whether NO related activation of key signaling pathways that mediate cell migration and invasion are dependent on the EGFR.

Herein, we demonstrate that iNOS is associated with poor outcome in TNBC patients $(n=209)$. We demonstrate that in BL2 TNBC, NO activation of the EGFR/ERK signaling pathway plays a direct role in the development of a pro-inflammatory phenotype that increases tumor cell invasive capacity. These results highlight a novel mechanism that may explain the observation that TNBC patients expressing iNOS display a worse prognosis. Additionally, these results highlight the potential of iNOS and EGFR as targets for consideration in the development of novel treatments for basal-like TNBC.

\section{RESULTS}

\section{iNOS predicts poor survival in TNBC}

We previously showed iNOS is a predictor of poor prognosis in a US cohort of ER-negative breast tumors but were unable to assess its role in TNBC [14]. Here we investigated the association of iNOS expression with recurrence free survival, metastasis free survival and breast cancer specific survival in 209 TNBC patients diagnosed in Ireland from 1999-2015 (Table 1 - Patient characteristics). TNBC tissue microarrays were stained for iNOS using immunohistochemistry and tumor epithelial iNOS expression assessed (Figure 1). As previously reported iNOS staining was predominantly observed in the tumor epithelia with few infiltrating immune cells staining positive for iNOS [14]. Recurrence free (local, regional or distant disease) survival analysis (Figure 2A) showed that iNOS positive tumors display decreased recurrence free survival compared to iNOS negative tumors, with low (Log-rank test: $p=0.067)$ to moderate $(p=0.010)$ levels of iNOS expression trending towards a significant association with disease recurrence. The highest levels of iNOS showed a trend towards decreased recurrence free survival but did not reach statistical significance $(\mathrm{p}=0.156)$. Metastasis free survival analysis (Figure 2B) showed that iNOS positive tumors have an increased chance of distant metastasis compared to iNOS negative tumors, with low (Log-rank test: $\mathrm{p}=0.029$ ) to moderate $(p=0.002)$ levels of iNOS expression significantly associated with the development of distant metastasis. Similar to disease-free survival, the highest levels of iNOS showed a trend towards increased metastasis but did not quite reach statistical significance $(p=0.065)$. Given that recurrence whether local, regional or distant is suggestive of aggressive progressive disease we then examined whether NOS2 predicts increased risk of dying from TNBC. Similarly when examining breast cancer specific survival, Figure $2 \mathrm{C}$ showed that iNOS positive tumors are associated with worse breast cancer specific survival compared to iNOS negative tumors, with low (Log-rank test: $p=0.020)$ to moderate $(p=0.006)$ levels of iNOS expression significantly associated with decreased survival. The highest levels of iNOS showed a trend towards decreased survival but did not reach statistical significance $(p=0.189)$. The lack of association with survival at the highest levels of iNOS may reflect the generation of NO levels that begin to switch from pro-tumorigenic effects to anti-tumorigenic effects as previously reviewed [7]. Cox regression survival analysis was performed in Table 2 to calculate the hazard ratios (HR) associated with iNOS levels and recurrence free survival, metastasis free survival and breast cancer specific free survival. Most notably low levels of iNOS were associated a breast cancer specific free survival HR of 4.8 (95\% Confidence Interval (CI) 1.11-20.41; $\mathrm{p}=0.035$ ), while intermediate levels are associated with a HR of $5.9(95 \%$ CI 1.37-25.64; $\mathrm{p}=0.017)$. iNOS remained a significant predictor of outcome in the multivariable analysis after adjustment for age at diagnosis, neoadjuvant therapy, tumor grade and histological subtype, with low levels of iNOS associated a breast cancer specific free survival HR of 5.0 (95\% Confidence Interval (CI) 1.16-21.94; 
Table 1: TNBC patient characteristics

\begin{tabular}{|c|c|}
\hline Characteristic & Median (Range) \\
\hline Age at Diagnosis (Years) $(n=209)$ & $57(30-91)$ \\
\hline \multicolumn{2}{|l|}{ Follow-Up (Months) } \\
\hline Recurrence Free Survival ( $\mathrm{n}=199)$ & $38(1-186)$ \\
\hline Metastasis Free Survival $(\mathrm{n}=200)$ & $40(1-186)$ \\
\hline \multirow[t]{2}{*}{ Breast Cancer Specific Survival $(n=200)$} & $46(1-186)$ \\
\hline & N (\%) \\
\hline \multicolumn{2}{|l|}{ Tumor Grade } \\
\hline Grade 2 & $27(13 \%)$ \\
\hline Grade 3 & $181(87 \%)$ \\
\hline Unknown & 1 \\
\hline \multicolumn{2}{|l|}{ Histological Type } \\
\hline Ductal & $171(82 \%)$ \\
\hline Lobular & $9(4 \%)$ \\
\hline Metaplastic & $11(5 \%)$ \\
\hline Mixed ductal & $2(1 \%)$ \\
\hline Papillary & $1(<0.5 \%)$ \\
\hline Medullary & $7(3 \%)$ \\
\hline Apocrine & $6(3 \%)$ \\
\hline Micropapillary & $1(<0.5 \%)$ \\
\hline Unknown & $1(<0.5 \%)$ \\
\hline \multicolumn{2}{|l|}{ Neoadjuvant Therapy } \\
\hline No & $183(88 \%)$ \\
\hline Yes & $26(12 \%)$ \\
\hline \multicolumn{2}{|l|}{ iNOS Levels } \\
\hline Negative & $28(13 \%)$ \\
\hline Weak & $83(40 \%)$ \\
\hline Moderate & $62(30 \%)$ \\
\hline Strong & $36(17 \%)$ \\
\hline \multicolumn{2}{|l|}{ Disease Free Survival* } \\
\hline No recurrence & $140(70 \%)$ \\
\hline Recurrence & $59(30 \%)$ \\
\hline \multicolumn{2}{|l|}{ Metastasis Free Survival* } \\
\hline No distant metastasis & $154(77 \%)$ \\
\hline Distant Metastasis & $46(23 \%)$ \\
\hline \multicolumn{2}{|l|}{ Breast Cancer Specific Survival** } \\
\hline Alive & $151(75 \%)$ \\
\hline Deceased & $49(25 \%)$ \\
\hline
\end{tabular}

*9 patients excluded due to distant metastasis at diagnosis, and 1 treated in another country and lost to follow-up.

**9 patients excluded due to death from other causes. $\mathrm{p}=0.031$ ), while intermediate levels are associated with a HR of $7.2(95 \%$ CI $1.60-32.34 ; \mathrm{p}=0.010)$ in the multivariable analysis (Table 2). Additionally we found that the percentage of tumor infiltrating lymphocytes (TILs) in the tumor adjacent stroma was highest in patients with iNOS negative tumors (Median \% TIL count $=17.5 \%$ ), and lowest in patients with iNOS moderate tumors $($ Median \% TIL count $=10 \%)($ Table 3$)$. TIL counts increased again in patients with iNOS high tumors (Median \% TIL count $=15 \%$ ). These results warrant further investigation as the literature suggests that low TIL counts are associated with worse outcomes in TNBC [15].

\section{NO activates EGFR signaling}

To investigate the impact of NO on basal-like cancer cells, we used three cell lines: MCF-10A normal immortalized basal breast cells, MDA-MB-468 BL1 TNBC cells and HCC1806 BL2 TNBC cells according to Lehmann's categories $[4,6]$. The basal expression levels of total EGFR and EGFR phosphorylation at Y1045, Y1068 and Y1173 are shown in Supplementary Figure 1A, while the basal levels of iNOS in these cell lines are show in Supplementary Figure 1B. We used increasing concentrations of the NO donor diethylenetriamine/nitric oxide adduct (DETA/NO), to assess the effects of NO on EGFR signaling, a marker of poor prognosis in basal-like TNBC $[16,17]$. The levels of DETA/NO used in this study are equivalent to 0 to $500 \mathrm{nM} \mathrm{NO}$, which are physiologically relevant as it is estimated that approximately $100 \mathrm{nM} \mathrm{NO}$ is required for the phosphorylation of Akt and $400 \mathrm{nM}$ for the phosphorylation of p53 in vitro $[18,19]$. The effects of DETA/NO observed in this study are unlikely to be mediated by the NO-cGMP axis, as cGMP is activated at levels equivalent to $<0.1 \mathrm{mM}$ DETA/NO [18, 19], and $0.5 \mathrm{mM}$ DETA/NO has been shown to suppress cGMP back to baseline levels [20]. Although NO has been shown to increase the phosphorylation status of EGFR residues [14], the downstream signaling effects remain unknown. We combined DETA/NO with the EGFR kinase inhibitor (PD153035) to study the reliance of NO on EGFR signaling. Phosphorylation on EGFR residues Y1045, Y1068 and Y1173 are recognized as being responsible for controlling EGFR signaling [21]. Figure $3 \mathrm{~A}$ and the corresponding densitometry analysis in Figure 4 demonstrates that 24 hour exposure to DETA/ NO increased EGFR phosphorylation in Y1173 in MDAMB-468 and Y1045, Y1068 and Y1173 in HCC1806 cell lines. No effect was seen in MCF-10A. Interestingly the BL2 cell line, HCC1806 cell line, shows a higher induction of EGFR phosphorylation compared the BL1 cell line MDA-MB-468, with the $0.5 \mathrm{mM}$ dose of DETA/NO showing the strongest affect. The increased phosphorylation was reverted to basal levels when the DETA/NO treatment is combined with $100 \mathrm{nM}$ of 
PD153035 in the HCC1806 for Y1045, Y1068 and Y1173 and in MDA-MB-468 for Y1173. Interestingly NO treatment also increased the expression of iNOS mRNA which was reversed with the addition of the EGFR Inhibitor PD153035 indicating a feed forward loop via the EGFR (Supplementary Figure 1C).

We next examined the effect of DETA/NO induced EGFR phosphorylation on ERK1/2 as one of its main downstream effectors. While $0.5 \mathrm{mM}$ of DETA/NO increased ERK1/2 activation in all cell lines, it was only statistically significant in HCC1806 as shown by the densitometry analysis in Figure 5. DETA/NO induction of ERK1/2 activation was reverted to below basal levels by the PD153035 only in the HCC1806 showing the specific EGFR-dependency of NO induction of ERK phosphorylation in this cell line (Figure 3B). ERK1/2 phosphorylation induced by DETA/NO was abrogated by combining the treatment with $200 \mathrm{nM}$ of MEK inhibitor PD198306 [22]. PD198306 showed significant activity in MDA-MB-468 and HCC1806, reducing ERK1/2 phosphorylation status in both basal and DETA/NO stimulated cells, indicating that NO activation of ERK is enhanced through MEK.

\section{EGFR activation by increased NO triggers a pro-inflammatory phenotype.}

$\mathrm{NO}$ is largely recognized as a pro-inflammatory biomolecule [23], and is implicated in the establishment of the pro-inflammatory phenotype [24]. To further investigate the interaction between $\mathrm{NO}$ and EGFR in basal-like breast cancer, we first examined the effect of DETA/NO on cyclooxygenase-2 (COX-2) expression, which is implicated in tumor progression and poor outcome in ER negative breast cancer [25-27]. 0.5mM DETA/NO induced COX-2 expression in the BL2 HCC1806, which was significantly abrogated by EGFR and $\mathrm{MEK} / \mathrm{ERK} 1 / 2$ inhibition, confirming the role of EGFR in COX2 induction (Figure 6). DETA/NO had no significant effect on COX-2 expression in the normal immortalized MCF-10A. COX-2 was not detectable in the BL1 MDA-MB-468 either at basal line or after DETA/NO treatment. Interleukin (IL)-1 $\beta$, IL-6, IL-8 and tumor necrosis factor alpha $(\mathrm{TNF} \alpha)$ are four cytokines involved in inflammation and wound healing [28-30]. We measured the levels of IL-1 $\beta$, IL- 6 and IL- 8 secretion 1,6 and 24 hours post treatment with $0.5 \mathrm{mM}$ DETA/ NO alone or in combination with 100nM PD153035. Figure 7 shows there is no consistent secretion pattern applicable for the three different cytokines. No effect of DETA/NO treatment on IL-6 expression was found in any cell lines (Figure 7A). Figure 7B shows IL-1 $\beta$ secretion was significantly increased in HCC1806 24 hours post exposure to DETA/NO, and could be partially reversed with the EGFR inhibitor. DETA/NO increase IL-1 $\beta$ secretion from MCF-10A or MDA-MB-468. Figure 7C demonstrates no stimulatory effect of DETA/NO on MCF10A secretion of IL-8; while both MDA-MB-468 and the HCC1806, show increased IL-8 secretion 24 hours post DETA/NO exposure compared to vehicle.

TNF $\alpha$ plays a central role in inflammation in cancer. Figure $8 \mathrm{~A}$ demonstrates that $\mathrm{TNF} \alpha$ secretion is significantly increased by $0.5 \mathrm{mM}$ DETA/NO compared to vehicle after 24 hours in both BL1 MDA-MB-468 and BL2 HCC1806 cells, but not in MCF-10A. The magnitude of TNF $\alpha$ induction in the HCC1806 was greater than the MDA-MB-468. Co-treatment with the EGFR inhibitor, significantly decreased $\mathrm{TNF} \alpha$ release to basal levels in HCC 1806 but not MDA-MB-468. This finding suggests a link between EGFR activation and the induction of a proinflammatory phenotype in the BL2 HCC1806. Nuclear factor-kappa $\mathrm{B}(\mathrm{NF}-\kappa \mathrm{B})$ meditates $\mathrm{TNF} \alpha$ signaling. When TNF $\alpha$ binds to its cell surface receptor, it triggers intracellular signaling resulting in the translocation of NF$\kappa \mathrm{B}$ to the nucleus and the activation of NF- $\kappa \mathrm{B}$ dependent gene expression [31]. We used a NF- $\kappa \mathrm{B}$ luciferase reporter to study the effect of NO levels on NF- $\kappa \mathrm{B}$ gene promoter dependent activity (Figure 8B). We show increased NF- $\kappa \mathrm{B}$ activity after DETA/NO exposure in the BL2 HCC1806 cell line, while we could see no significant effect in neither

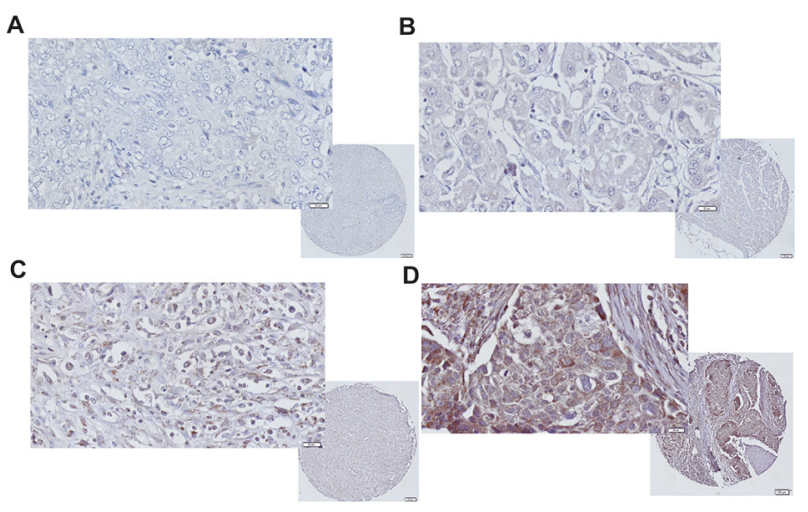

Figure 1: iNOS expression immunohistochemistry in TNBC. Representative images of TNBC tumor with (A) negative, (B) low, (C) moderate, and (D) strong iNOS tumor epithelial staining. 


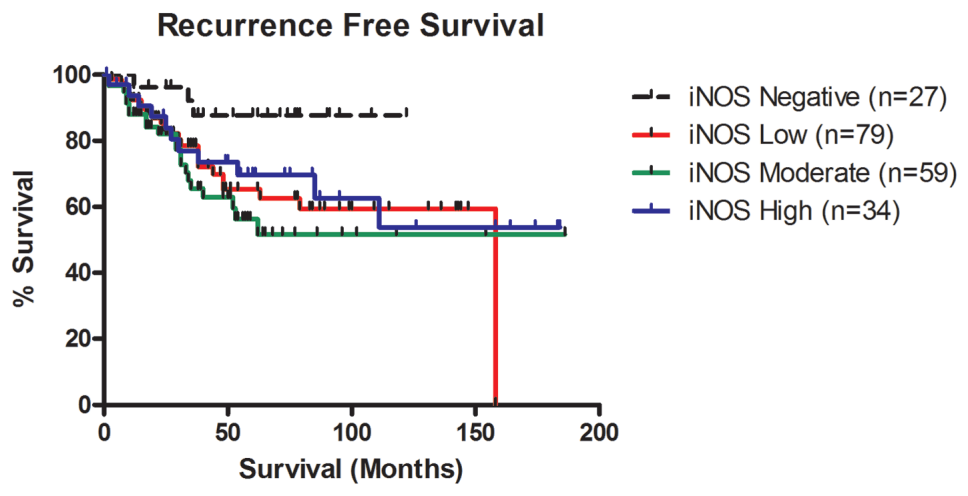

B

\section{Distant Metastasis Free Survival}

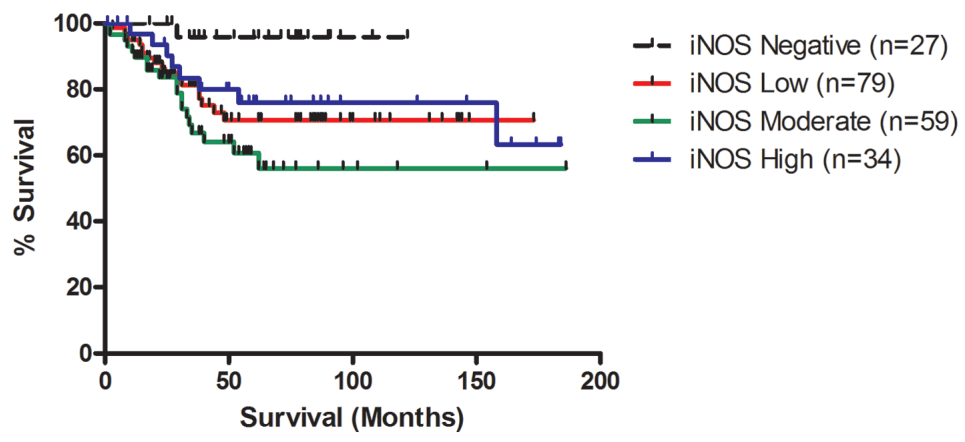

C

Breast Cancer Specific Survival

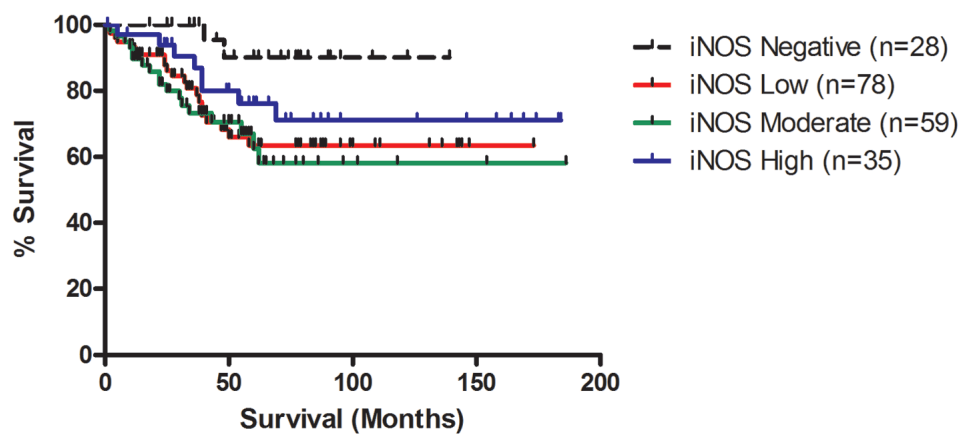

Figure 2: iNOS expression is associated with decreased recurrence free survival, distant metastasis free survival and breast cancer survival in TNBC. (A) Kaplan-Meier cumulative recurrence free survival curves for TNBC patients by iNOS status $(n=199)$. Patients with weak iNOS expression $(n=79)$ or moderate iNOS expression $(n=59)$ were significantly associated with decreased recurrence free survival compared to patients with negative iNOS expression $(\mathrm{n}=27)(\mathrm{P}=0.036 \& \mathrm{P}=0.007, \log$-rank test). Patients with strong iNOS expression $(n=34)$ showed a trend toward worse survival compared to patients with negative iNOS expression $(n=27)$, but did not reach significance ( $\mathrm{P}=0.078$, log-rank test). (B) Kaplan-Meier cumulative distant metastasis free survival curves for TNBC patients by iNOS status $(n=199)$. Patients with weak iNOS expression $(n=79)$ or moderate levels of iNOS expression $(n=59)$ were significantly associated with increased risk of distant metastasis compared to patients with negative iNOS expression $(\mathrm{n}=27)(\mathrm{P}=0.017 \& \mathrm{P}=0.002, \log$ rank test). Patients with strong iNOS expression $(\mathrm{n}=34)$ showed a trend toward increased risk of distant metastasis compared to patients with negative iNOS expression $(\mathrm{n}=27)$, but did not reach significance $(\mathrm{P}=0.052$, log-rank test). $(\mathrm{C})$ Kaplan-Meier cumulative breast cancer-specific survival curves for TNBC patients by iNOS status $(n=200)$. Patients with weak iNOS expression $(n=78)$ or moderate levels of iNOS expression $(n=59)$ were significantly associated with increased risk of death due to breast cancer compared to patients with negative iNOS expression $(\mathrm{n}=28)(\mathrm{P}=0.012 \& \mathrm{P}=0.007$, log-rank test $)$. Patients with strong iNOS expression $(\mathrm{n}=35)$ showed a trend toward increased risk of distant metastasis compared to patients with negative iNOS expression $(n=28)$, but did not reach significance $(\mathrm{P}=0.093$, log-rank test $)$. 


\section{Univariate Cox Regression Analysis}

HR

iNOS Levels \& Disease Free Survival*

Negative

Low

Moderate

High

iNOS Levels \& Metastasis Free Survival*

Negative

Low

Moderate

High

High

iNOS Levels \& Breast Cancer Specific Survival

Negative

Low

Moderate

High
1.0

3.5

4.4

3.0

1.0

8.0

12.1

6.5
95\% Confidence Interval
$P$-value

$\mathbf{N}$

(1)

\begin{tabular}{|c|c|c|c|c|}
\hline \multicolumn{5}{|c|}{ Multivariable Cox Regression Analysis** } \\
\hline & HR & $\begin{array}{l}\text { 95\% Confidence } \\
\text { Interval }\end{array}$ & $P$-value & \\
\hline \multicolumn{5}{|c|}{ iNOS Levels \& Disease Free Survival } \\
\hline Negative & 1.0 & & & 27 \\
\hline Low & 3.5 & $1.04-11.51$ & 0.044 & 79 \\
\hline Moderate & 4.6 & $1.35-15.79$ & 0.015 & 59 \\
\hline High & 2.8 & $0.75-10.12$ & 0.127 & 33 \\
\hline \multicolumn{5}{|c|}{ iNOS Levels \& Metastasis Free Survival } \\
\hline Negative & 1.0 & & & 27 \\
\hline Low & 7.9 & $1.05-59.49$ & 0.044 & 79 \\
\hline Moderate & 12.7 & $1.67-95.91$ & 0.014 & 59 \\
\hline High & 6.1 & $0.75-49.76$ & 0.091 & 34 \\
\hline \multicolumn{5}{|c|}{ iNOS Levels \& Breast Cancer Specific Survival } \\
\hline Negative & 1.0 & & & 28 \\
\hline Low & 5.3 & $1.24-22.90$ & 0.024 & 78 \\
\hline Moderate & 6.2 & $1.43-27.13$ & 0.026 & 59 \\
\hline High & 3.2 & $0.67-15.15$ & 0.142 & 34 \\
\hline
\end{tabular}

*Adjusted for age at diagnosis, no chemotherapy/neoadjuvant/adjuvant chemotherapy/unknown, tumor grade, histological subtype. 
Table 3: Association between iNOS levels and \% sTILs

\begin{tabular}{lcccc}
\hline iNOS Levels & Median \% sTILS & Range & Pvalue* & N \\
\hline Negative & 17.5 & $5-90$ & Ref & 79 \\
Low & 15.0 & $2-80$ & 0.272 & 59 \\
Moderate & 10.0 & $0-80$ & 0.038 & 34 \\
High & 15.0 & $2-80$ & 0.177 & 34 \\
\hline
\end{tabular}

*Kwallis non-parametric test comparing sTILs levels in iNOS low, moderate and high tumors to iNOS negative tumors.

the MCF-10A nor the BL1 MDA-MB-468 cells, which reflects the higher levels of TNF $\alpha$ induced by DETA/ $\mathrm{NO}$ in Figure 8A. To confirm a direct TNF $\alpha$ mediated effect, we used the TNF $\alpha$ blocking antibody Infliximab to investigate the effect of the NO induced TNF $\alpha$ on $\mathrm{NF}-\kappa \mathrm{B}$ activity. Our findings indicate a significant decrease in NF$\kappa \mathrm{B}$ induced activity in the $\mathrm{HCC} 1806$ when we combined Infliximab with DETA/NO. Together, these findings suggest a direct role for NO, triggering a pro-inflammatory phenotype in the BL2 cells, mediated by EGFR and NF$\kappa \mathrm{B}$ activation.

\section{NO regulates migration and invasion capability}

Inflammation is a major driving force in cancer metastasis $[32,33]$. IL-8 is a pro-inflammatory cytokine

A

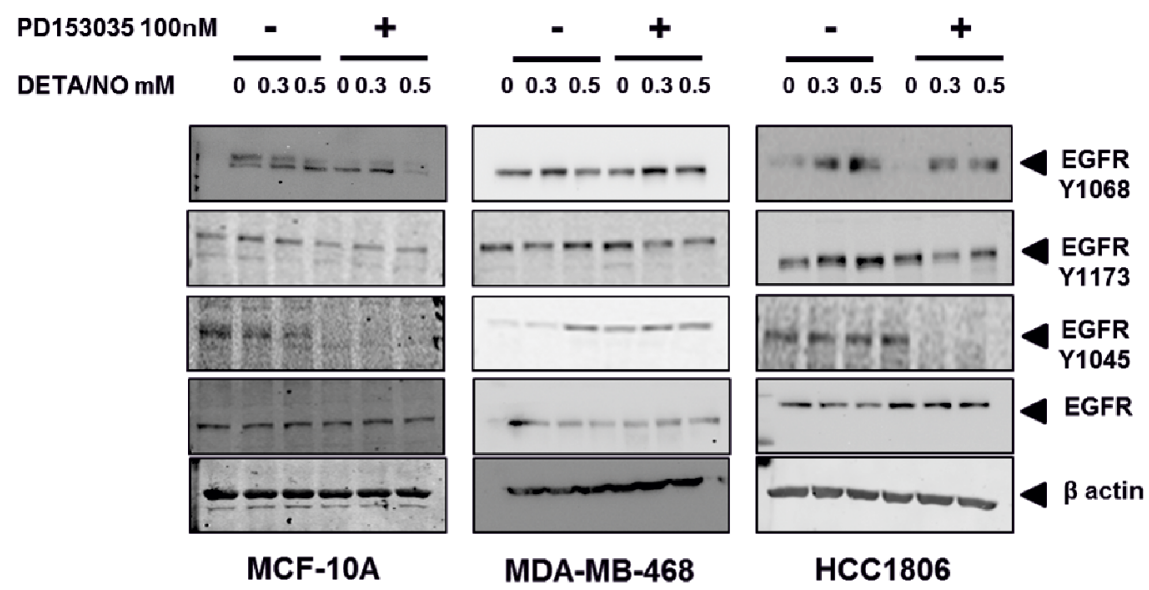

B

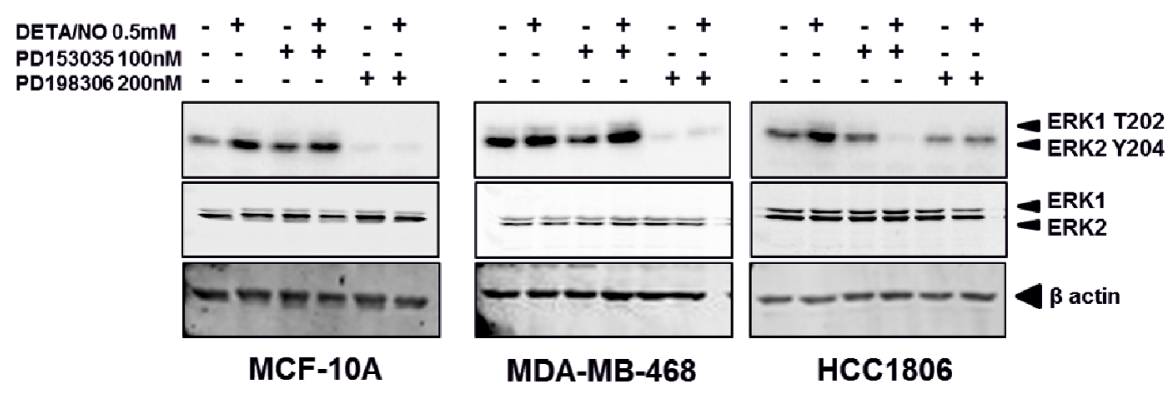

Figure 3: NO induces increased EGFR and ERK phosphorylation in TNBC cell lines. Phosphorylation status of EGFR (A) in the MCF-10A, MDA-MB-468 and HCC1806 cell lines after 24 hours exposure to increasing doses of DETA/NO alone or in combination with 100nM of PD153035 (EGFR inhibitor). (B) Phosphorylation status of the MAP kinases ERK1 and ERK2 after 24 hours exposure to $0.5 \mathrm{mM}$ of DETA/NO alone or in combination with 100nM of PD153035 or 200nM PD198306 (MEK inhibitor). 

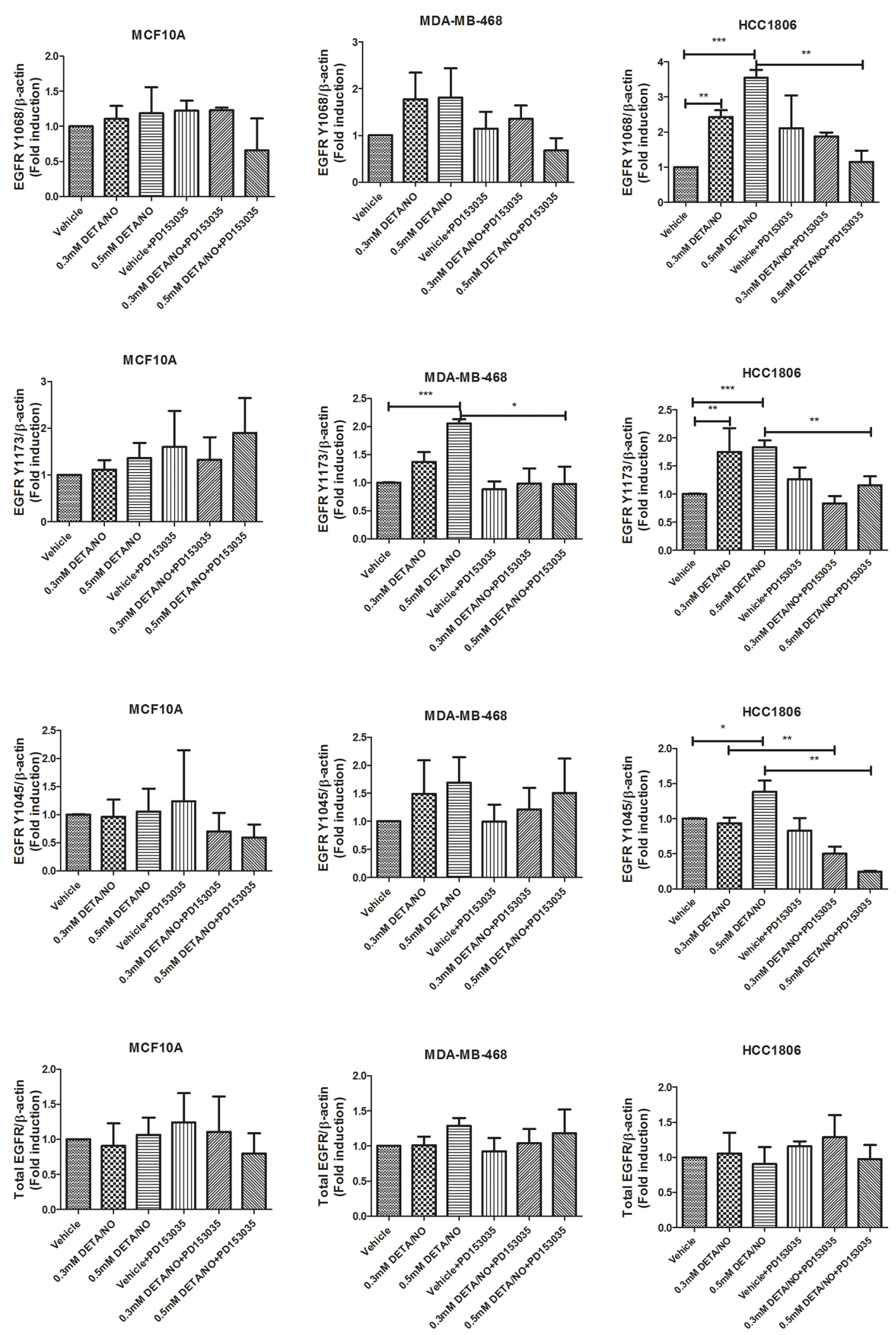

Figure 4: Densitometry analysis of EGFR phosphorylation in response to DETA/NO. Quantification of western blots (Figure 3A) examining EGFR phosphorylation at Y1068, Y1173 and Y1045 and total EGFR expression in the MCF-10A, MDA-MB-468 and HCC1806 cell lines after 24 hours exposure to increasing doses of DETA/NO alone or in combination with 100nM of PD153035 (EGFR inhibitor). 
which induces matrix metalloproteinase (MMP9) expression and cleavage in different biological systems $[34,35]$. To determine if the induction of IL-8 secretion in MDA-MB-468 and HCC1806 by DETA/NO as seen in Figure $7 \mathrm{C}$, reflects the invasive potential of the TNBC cell lines we examined the effects of DETA/NO on MMP expression, and migration and invasion potential. $0.5 \mathrm{mM}$ DETA/NO increased levels of MMP1 and MMP9, but not MMP2 mRNA in all three cells lines (Figure 9A). To confirm that changes in gene expression translated to its biological activity we assessed DETA/NOs effect on MMP2 and MMP9 activity by gelatin zymography
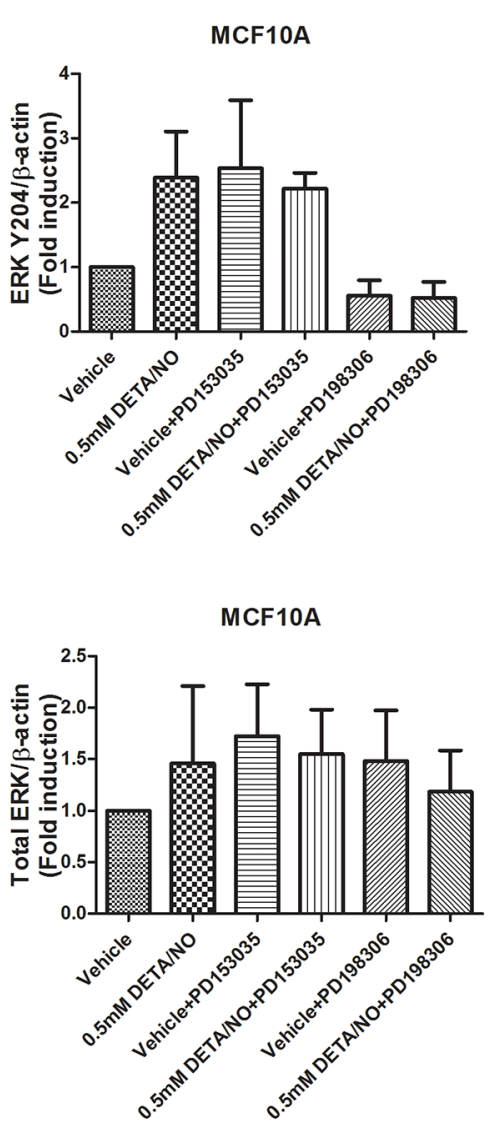
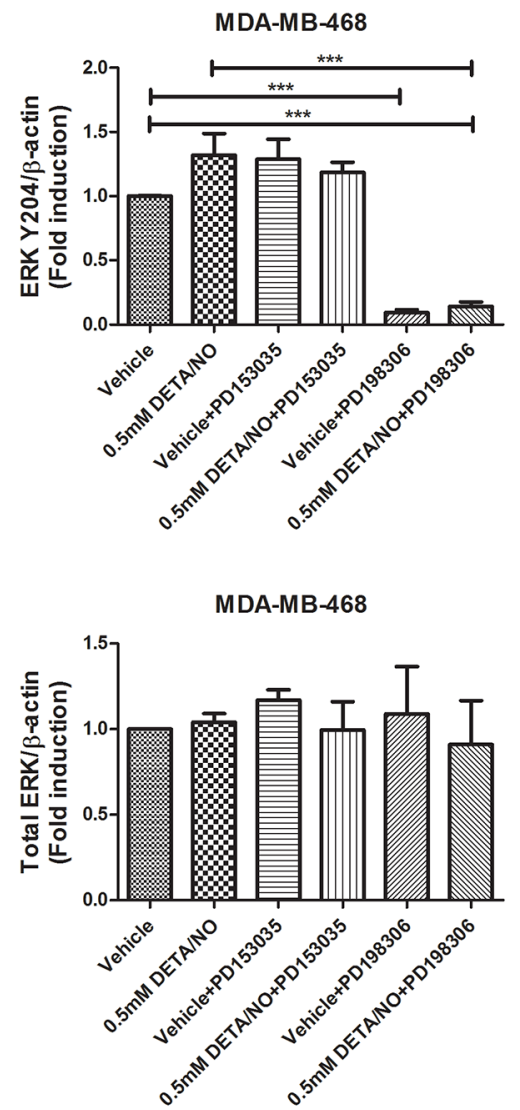
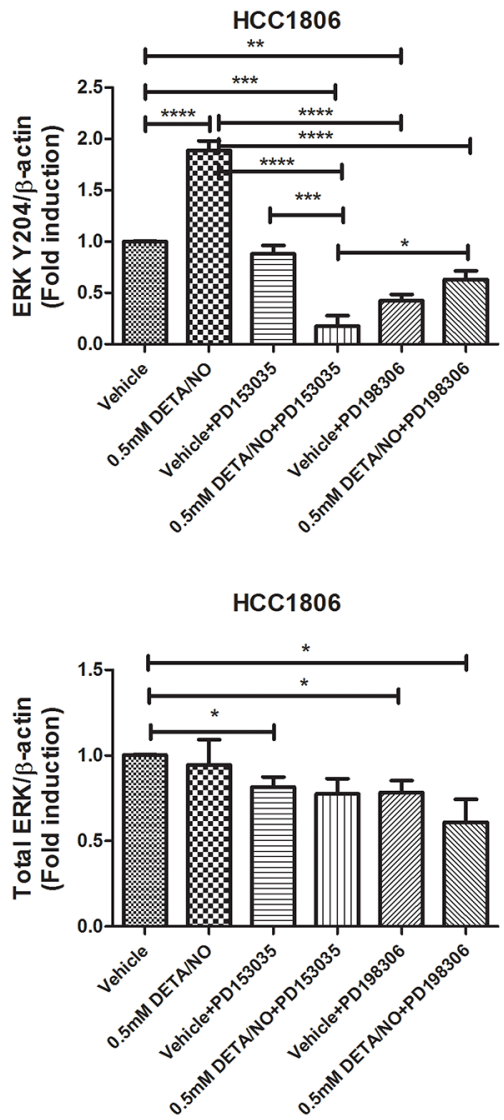

Figure 5: Densitometry analysis of ERK phosphorylation in response to DETA/NO. Quantification of western blots (Figure 3B) examining ERK phosphorylation at Y204 and total ERK expression in the MCF-10A, MDA-MB-468 and HCC1806 cell lines after 24 hours exposure to increasing doses of DETA/NO alone or in combination with 100nM of PD153035 (EGFR inhibitor) or 200nM PD198306 (MEK inhibitor).

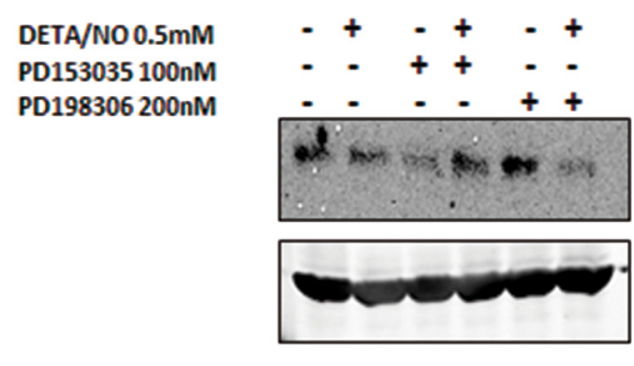

MCF-10A

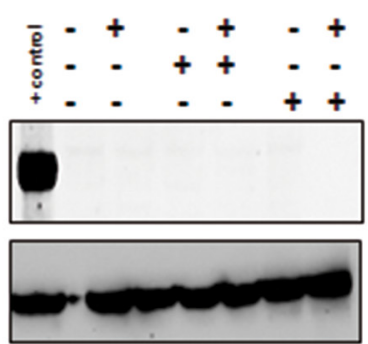

MDA-MB-468

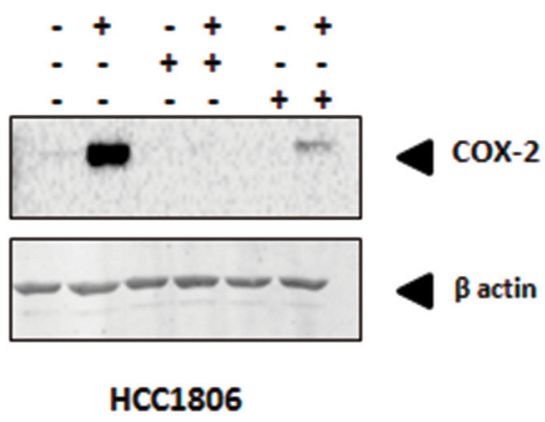

HCC1806

Figure 6: Induction of COX-2 by NO in HCC1806 is suppressed by EGFR or MEK inhibitiors. COX-2 protein levels in MCF-10A, MDA-MB-468 and HCC1806 after 24 hours exposure to $0.5 \mathrm{mM}$ of DETA/NO alone or in combination with $100 \mathrm{nM}$ of PD153035 or 200nM PD198306. 

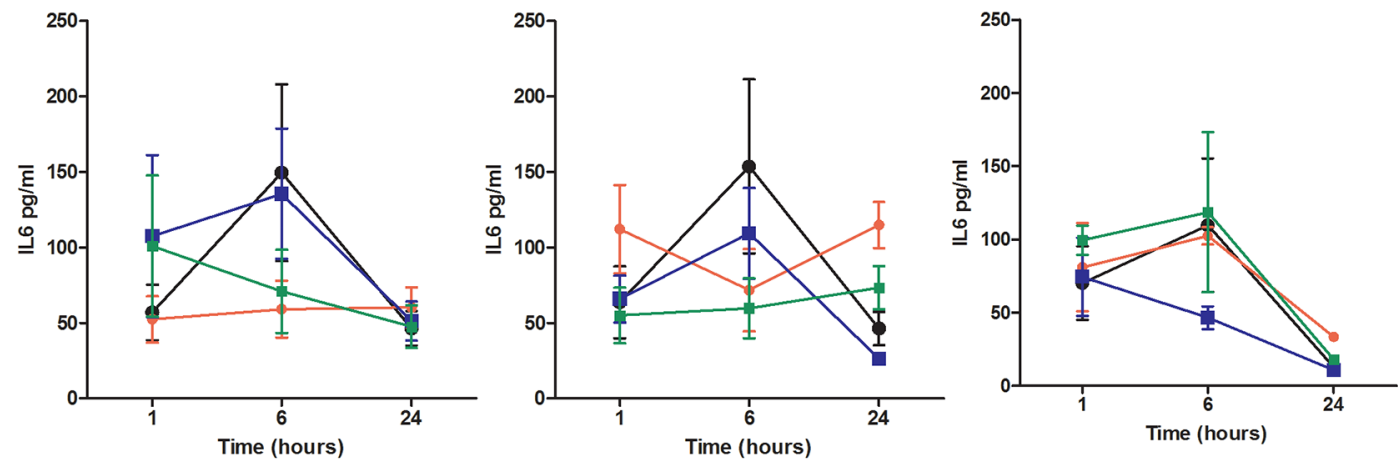

B
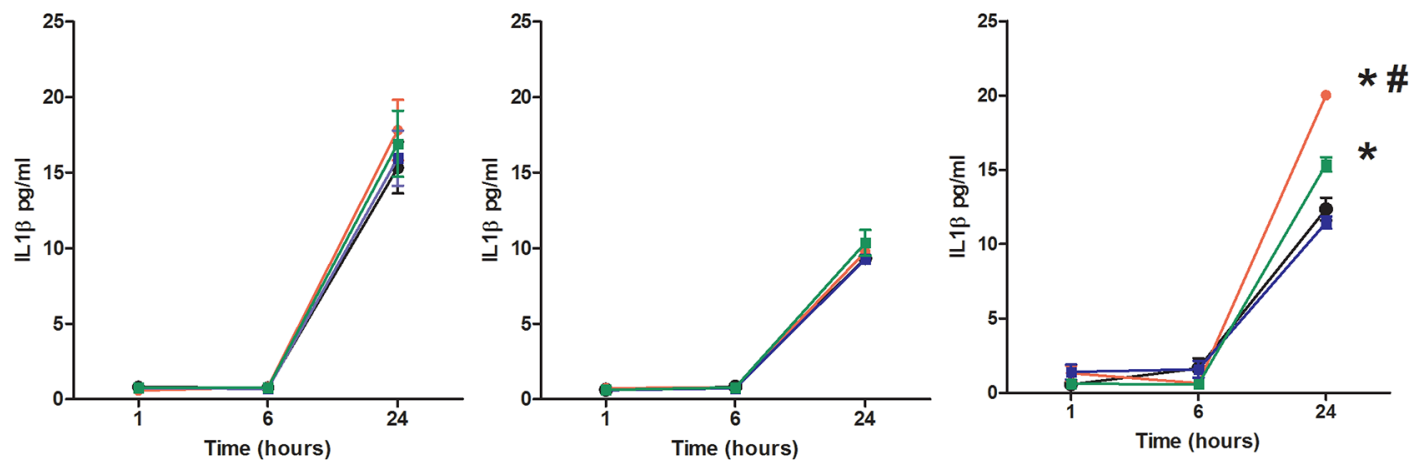

C
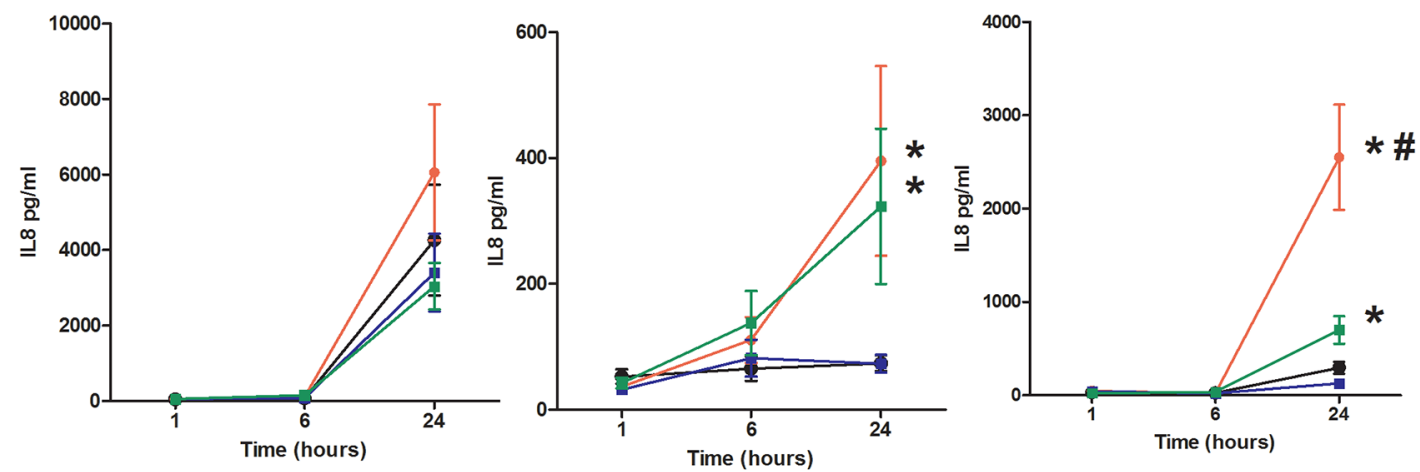

$\mathrm{NC}=0.5 \mathrm{DO} \rightarrow \mathrm{NC}+\mathrm{PD} 153035 \rightarrow 0.5 \mathrm{DO}+\mathrm{PD} 153035$

Figure 7: NO induction of IL-1 $\beta$ and IL-8 secretion is perturbed by EGFR inhibition in HCC1806. Cytokine profiling of released IL-6 (A) IL-1 $\beta$ (B) and Il-8 (C) in MCF-10A, MDA-MB-468 and HCC1806 after 24 hours exposure to vehicle or $0.5 \mathrm{mM}$ of DETA/NO alone or in combination with $100 \mathrm{nM}$ of PD153035. * $\mathrm{p}<0.05$ vs vehicle; $\# \mathrm{p}<0.05$ vs DETA/NO plus PD153035 
(Figure 9B). Surprisingly, the MCF-10A exhibited higher basal MMP activity than the cancer cell lines, with no significant effect of $0.5 \mathrm{mM}$ DETA/NO treatment on gelatinase activity. HCC1806 showed increased MMP9 activity after 24 hours exposure to DETA/NO, which was partially reversed in combination with the EGFR antagonist. DETA/NO had no significant effect on gelatinase activity in the MDA-MB-468.

Tumor cells undergo migration and invasion during metastasis [36]. These mechanisms are considered identical to those exerted by non-neoplastic cells in physiological processes such as wound healing [37]. We examined the effect of $0.5 \mathrm{mM}$ DETA/NO on cellular migration and invasion capacity across a FBS gradient ( 5 to $10 \%$ ) through $8 \mu \mathrm{m}$ trans-wells either uncoated (migration) or coated (invasion) (Figure 10 and Figure 11 (representative images)). $0.5 \mathrm{mM}$ DETA/NO significantly decreased the migration potential of normal MCF-10As, and conversely increased migration in both basal-like TNBC cell lines, with a greater increase seen in BL2

\section{A}

MCF-10A

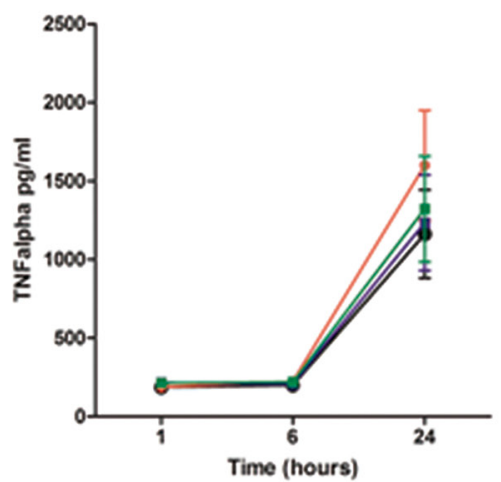

MDA-MB-468

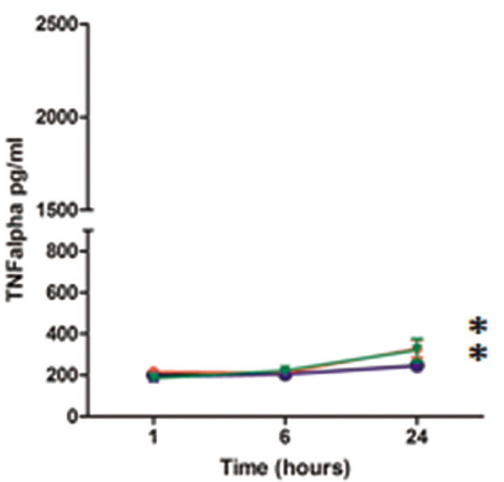

HCC1806

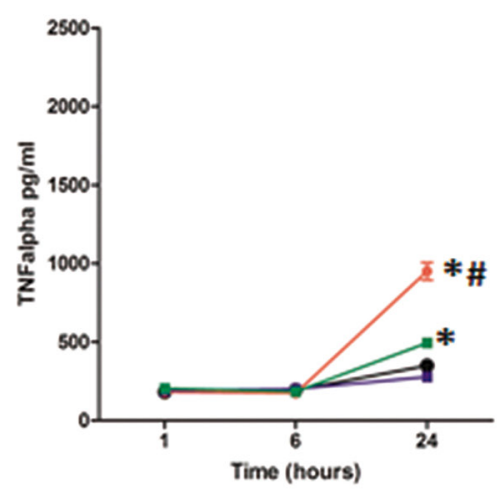

$\because \mathrm{NC} \rightarrow 0.5 \mathrm{DO}$

NC+PD153035

$0.5 \mathrm{DO}+\mathrm{PD} 153035$

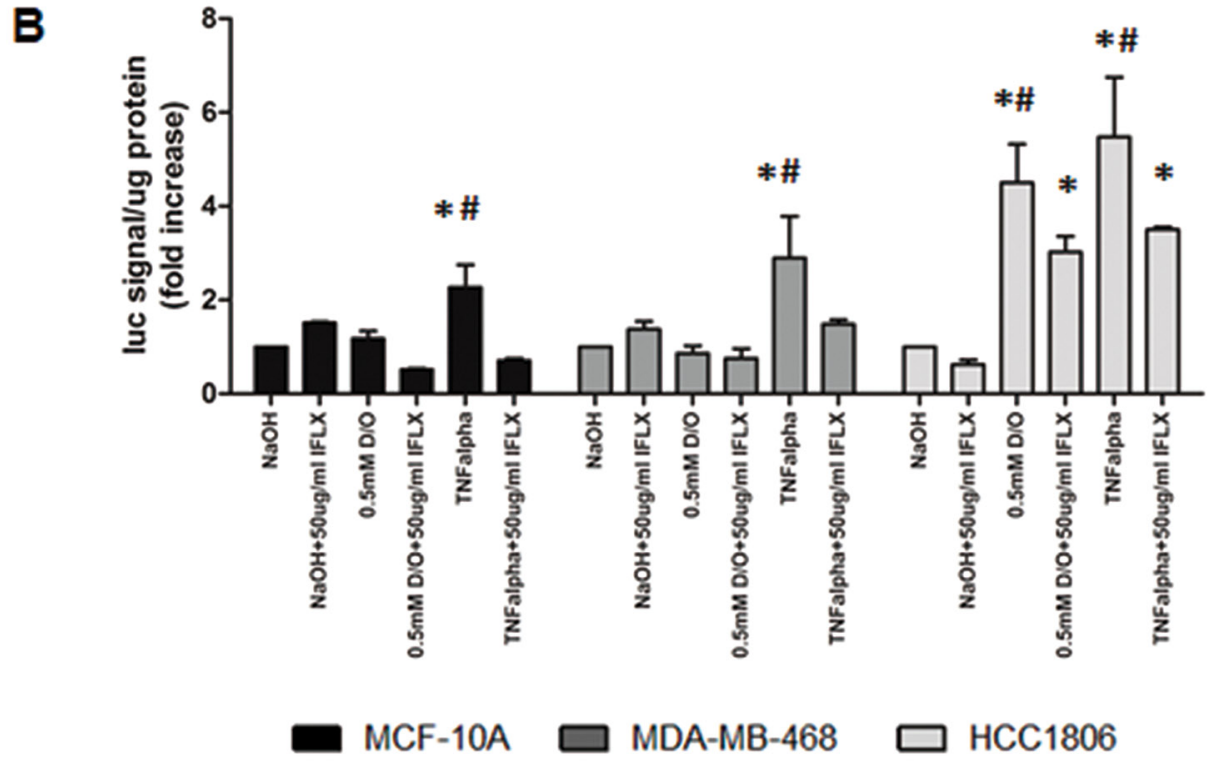

Figure 8: NO induces increased TNFa secretion and activation of NF-кB in HCC1806. TNF $\alpha$ released (A) in the three cell lines after 24 hours exposure to vehicle or $0.5 \mathrm{mM}$ of DETA/NO alone or in combination with 100nM of PD153035. (B) Luciferase activity of NF- $\kappa \mathrm{B}$ reporter after 24 hours exposure to vehicle or $0.5 \mathrm{mM}$ of DETA/NO alone or in combination with $50 \mu \mathrm{g} / \mathrm{ml}$ of Infliximab (TNF $\alpha$ blocking antibody), $10 \mathrm{ng} / \mathrm{ml}$ of recombinant TNF $\alpha$ were used as a positive control. ${ }^{*} \mathrm{p}<0.05$ vs vehicle; \# $\mathrm{p}<0.05$ vs DETA/NO plus PD153035. 
HCC1806 compared to BL1 MDA-MB-468. DETA/ NO mediated migration was dependent on the EGFR/ ERK activation, as either EGFR (PD153035) or MEK (PD198306) inhibition reverted migration levels to baseline. Similar patterns were observed for invasive capacity (Figure 9A). DETA/NO also increased the rate of HCC1806 invasion through gelatin (Figure 9B), and collagen coated surfaces (Figure 9C) confirming the effect observed on MMP-9 activity by zymography, and also indicating that DETA/NO may increase MMP1 enzymatic activity in addition to mRNA levels. In contrast, the MDA-MB-468 cells do not show any difference in the invasive capability after DETA/NO exposure, and the MCF-10A show a reduced invasive capacity similar to their migration capacity. Neither the EGFR nor the MEK inhibitors had any significant effect on MCF-10A or MDA-MB-468 invasive potential. These results reiterate, the dependency of BL2 TNBC cells on growth factor signaling, making them more sensitive to NO-related effects. These findings support the idea that high NO levels, produced by increased iNOS expression, trigger a loop where EGFR-ERK and NF- $\kappa \mathrm{B}$ are the main effectors, and implicate iNOS in TNBC progression.

\section{DISCUSSION}

Finding new targets for the treatment of TNBC is of major clinical importance. TNBCs have a high risk of local and distant recurrence, particularly in the first three years post diagnosis. TNBCs account for $15-20 \%$ of all breast cancers and are associated with an earlier onset, BRCA1 mutations and patients of African descent [38]. Current treatment strategies involve surgical intervention coupled with standard chemotherapy (anthracyclines, taxanes, cyclophosphamide), in the neoadjuvant or adjuvant setting. Recent clinical trials have focused around platinum agents and PARP inhibitors (particularly in BRCA1 associated TNBC), androgen receptor antagonists (LAR TNBC) and immune checkpoint inhibitors (TNBCs with high levels of tumor infiltrating lymphocytes) [38].

We previously showed that iNOS is a predictor of poor survival in ER-negative breast cancer $(n=98)$,

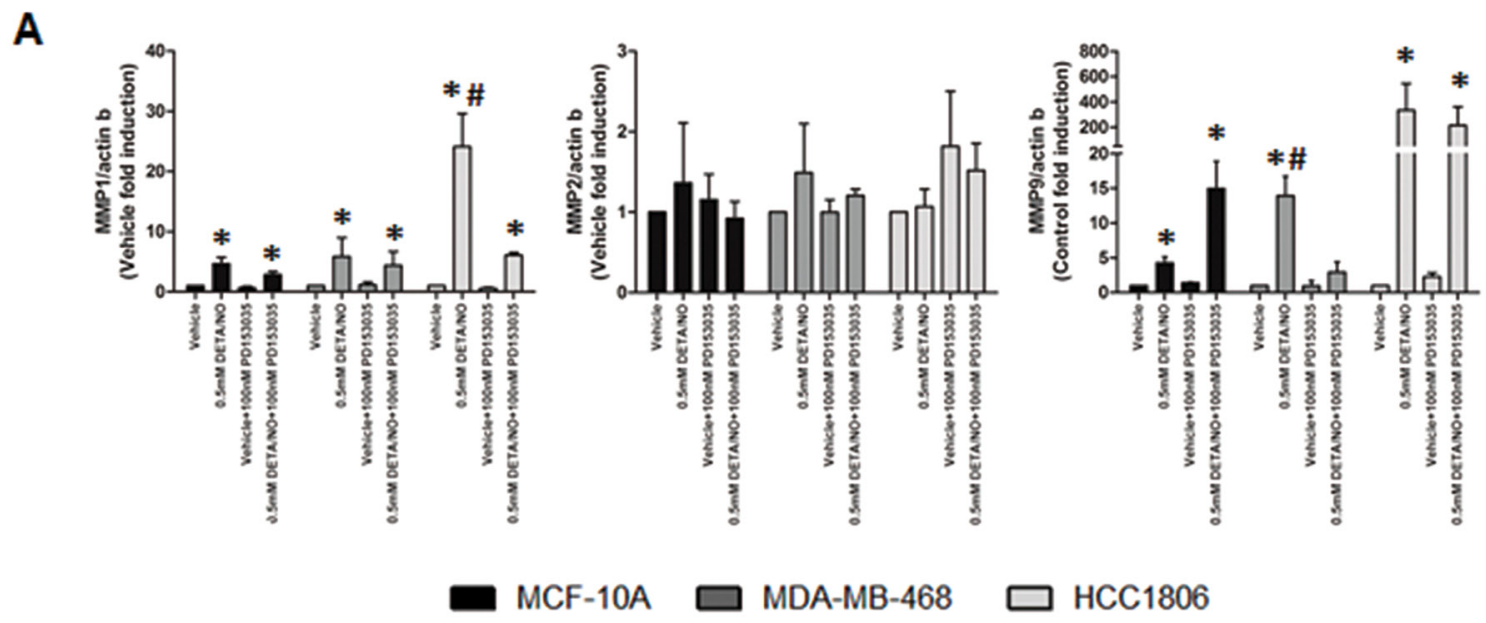

B

MCF-10A

MDA-MB-468

HCC1806
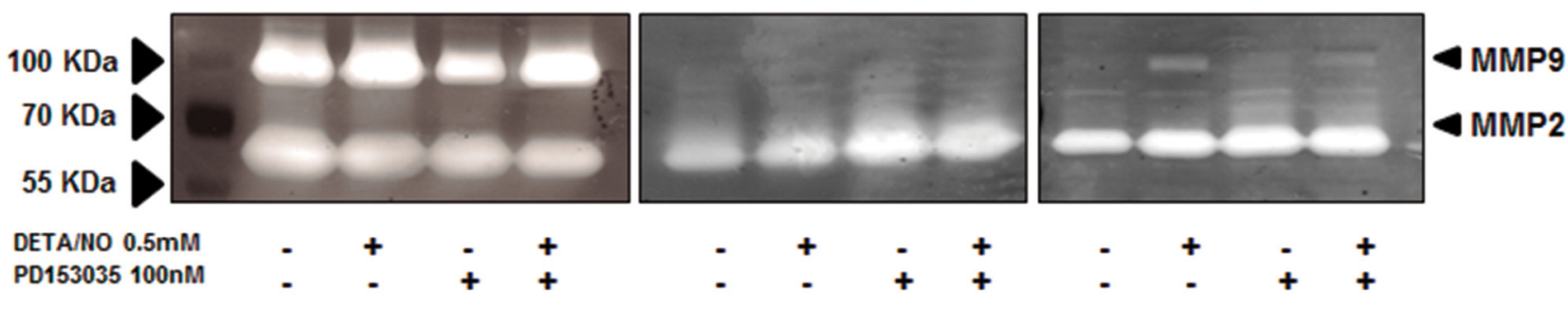

Figure 9: NO induces increased MMP expression and activity. (A) qPCR showing the mRNA expression levels of MMP1, MMP2 and MMP9 after 24 hours exposure to vehicle or $0.5 \mathrm{mM}$ of DETA/NO alone or in combination with 100nM of PD153035. (B) Zymography showing the gelatinase activity of MMP9 and MMP2 after 24 hours exposure to vehicle or 0.5mM of DETA/NO alone or in combination with 100nM of PD153035. 
but not in ER-positive breast cancer in a cohort of US patients [14]. We further demonstrated that iNOS was associated with EGFR phosphorylation, basal-like transcription patterns, and predicted poor outcome in patients with basal-like breast cancer $(n=41)$ [14]. Subsequently, we showed that NO autophosphorylates the EGFR via S-nitrosylation [9]. In 2015 GranadosPrincipal et al demonstrated an association between high levels of iNOS and decreased relapse free survival in 83 cases of TNBC [39]. Moreover in 2014, Heinecke

A

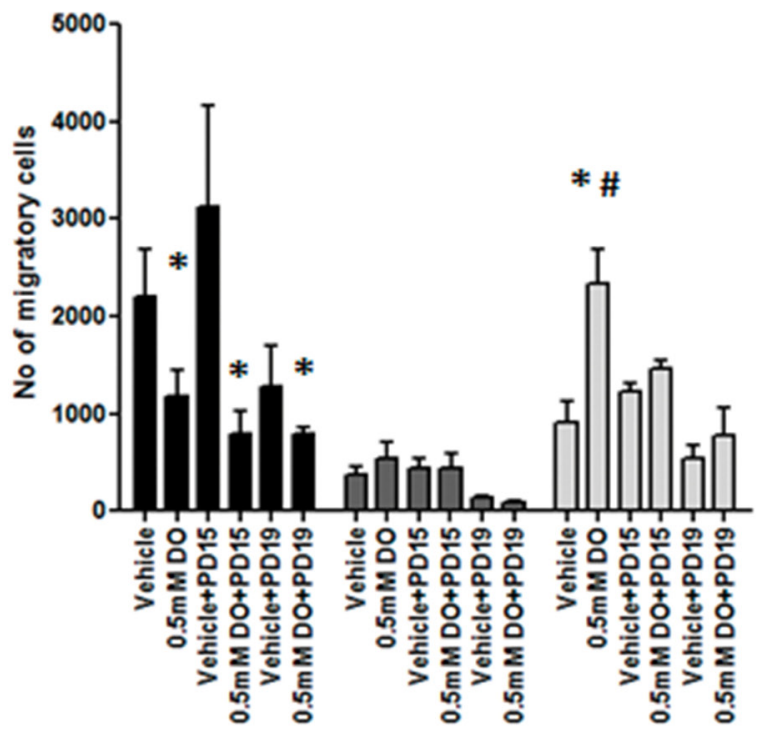

et al demonstrated that TNBC tumor proliferation and metastases to the brain were significantly suppressed by iNOS inhibition in nude mice [23], recapitulated by Granados-Principal et al [39]. Herein we demonstrate in an Irish cohort of 209 TNBC patients that iNOS predicts decreased overall survival, which includes patients with basal-like TNBC $(n=136)$, corroborating our previous findings and validating iNOS as a predictor of poor outcome in patients from different geographic regions (USA and Ireland).

B

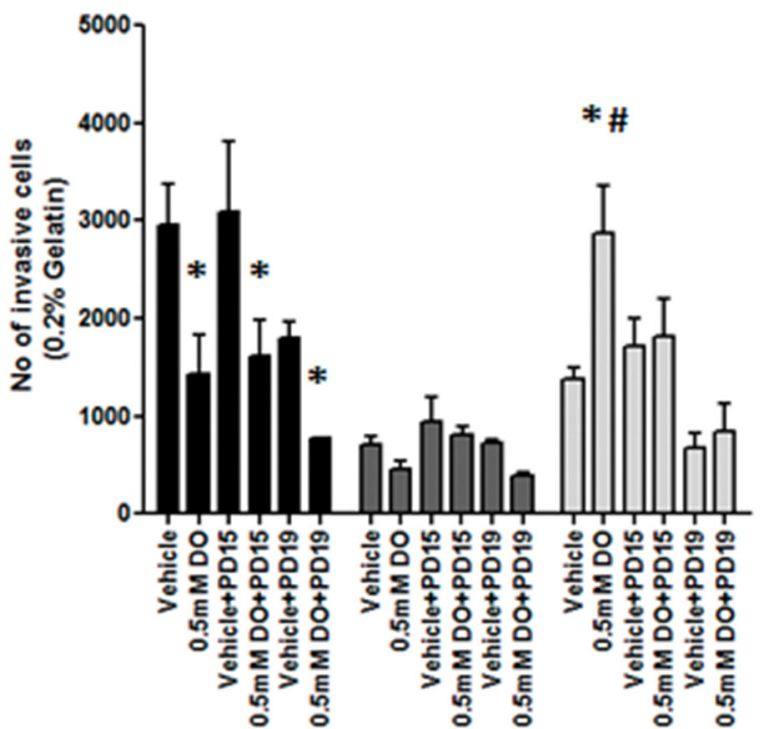

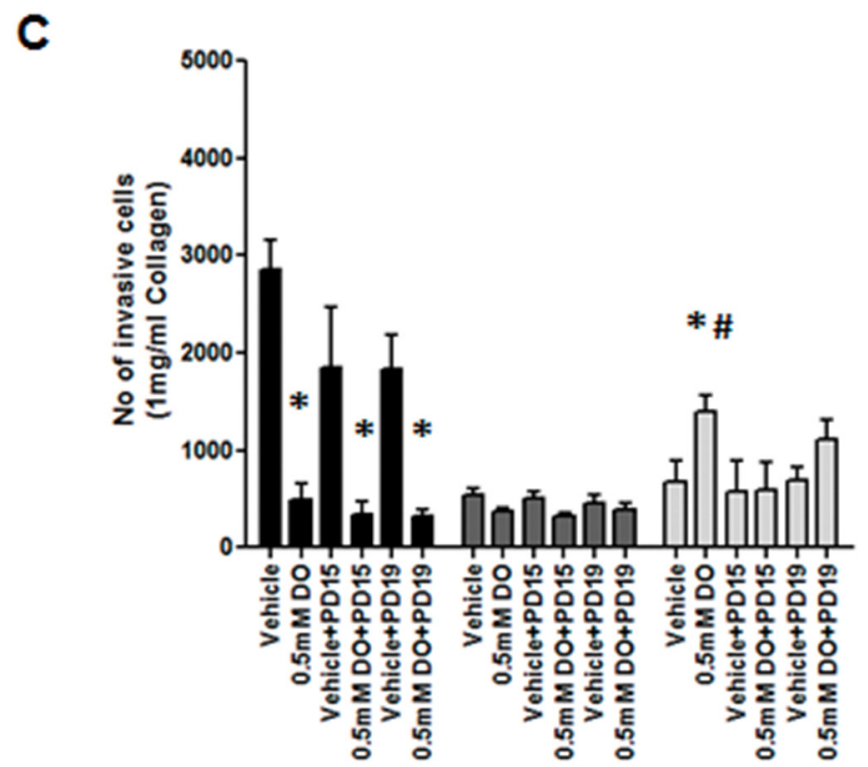

Figure 10: Impact of EGFR inhibition on NO induction of cell migration and invasion. (A) Cell migration, or invasion through (B) gelatin and (C) collagen after 24 hours exposure to vehicle or $0.5 \mathrm{mM}$ of DETA/NO alone or in combination with $100 \mathrm{nM}$ of PD153035 or 200nM PD198306.* $\mathrm{p}<0.05$ vs vehicle; \# $\mathrm{p}<0.05$ vs DETA/NO plus PD153035. 
With Lehmann et al's identification of six TNBC molecular subtypes (BL1, BL2, immunomodulatory, mesenchymal, mesenchymal stem like and LAR) based on gene expression profiles [4], and their further refinement into four TNBC molecular subtypes (BL1, BL2, mesenchymal, and LAR) [6], it becomes apparent that there are two different basal-like tumor biology's at play. Within the basal-like tumors, BL2 TNBC are characterized by a greater dependency on growth factor signaling including the EGFR, as opposed to BL1 where the tumors are mainly driven by cell cycle genes and BRCA mutations [4]. Given this further subdivision of the basal-like phenotype we examined whether increased levels of NO influence basal-like breast cancer cells, and

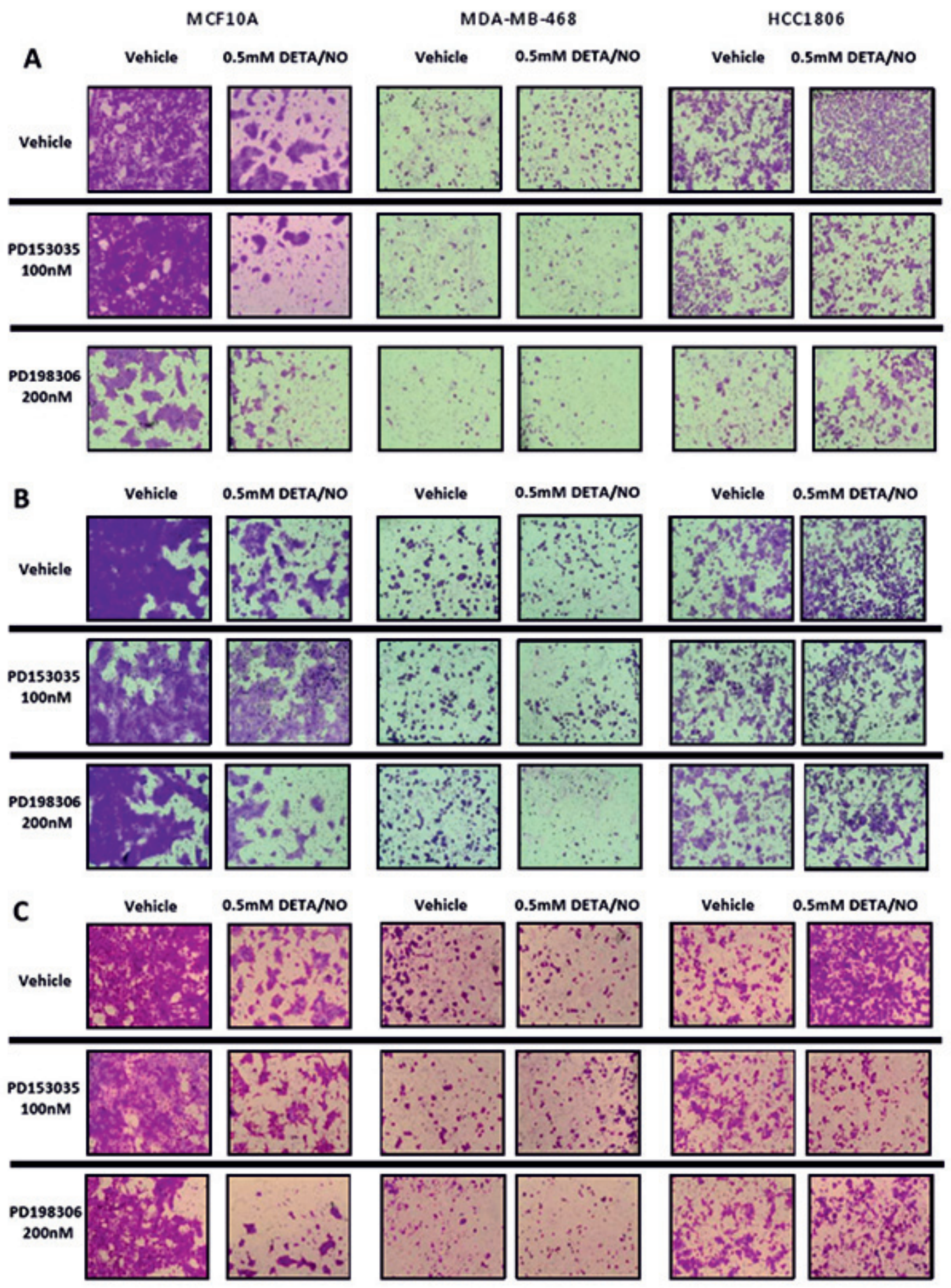

Figure 11: Representative images of NO effects on migration and invasion. Representative images of migratory and invasion potential (A) and invasive potential of the cell lines to invade through a $0.2 \%$ gelatin (B) or $1 \mathrm{mg} / \mathrm{ml}$ collagen (C) of the cell lines after 24 hours exposure to vehicle or $0.5 \mathrm{mM}$ of DETA/NO alone or in combination with 100nM of PD153035 or 200nM PD198306. 
regulate their pro-inflammatory and metastatic capacities in the context of BL1 and BL2 phenotypes. While both cell lines representing the BL1 and BL2 subtypes, displayed increased EGFR phosphorylation in response to DETA/NO not only in the previously reported Y1045 and Y1173 residues [14], but also in Y1068, the effect was greater on the BL2 cell line HCC1806. It should be noted that the induction of Y1045 was modest at best which may reflect our previous observation that Y1045 was phosphorylated within 10 mins exposure to DETA/ NO [14], and therefore there may be some degree of a negative feedback loop at 24 hours post incubation. The activation of the Y1068 by DETA/NO directly links NO mediated EGFR activation with ERK/MAPK activation [21], which we demonstrated was abrogated by the inclusion of the MEK/ERK inhibitor PD198306 [40]. This induction of ERK activation was dependent on the EGFR in the BL2 HCC1806 but not the BL1 MDA-MB-468 as demonstrated by the effects of EGFR inhibition on ERK phosphorylation after DETA/NO exposure, supporting the reported dependency of the BL2 subtype on growth factor receptor signaling [4]. It should be noted however that the MEK inhibitor did repress ERK phosphorylation below base line (to approx. 50\% of baseline) in the HCC 1806 , and while DETA/NO did increase ERK phosphorylation in the presence of the MEK inhibitor, it was unable to fully return ERK phosphorylation back to baseline levels. High levels of ERK expression have previously been shown to be associated with poor outcome in TNBC [41]. Contributing factors in this association may include ERK induction of IL-8 leading to increased migration and invasion and anchorage independent growth [42]. Indeed ERK inhibition in TNBC cells inhibits epithelial to mesenchymal transition, targets stem cell proliferation inhibits TNBC xenograft lung metastasis development in nude mouse models [43].

Furthermore, we show that the activation of the EGFR/ERK/MAPK pathway has a critical role in the development of a pro-inflammatory phenotype induced by DETA/NO. COX-2 has been reported to be overexpressed in breast cancer compared to normal breast tissue [44, 45]. Its main metabolite, prostaglandin E2 (PGE2) has been shown to promote migration, invasion, proliferation and angiogenesis while inhibiting apoptosis $[46,47]$. In this regard, we show that the activation of EGFR and ERK, by DETA/NO drives COX-2 overexpression in the BL2 HCC1806. However, it had no effect in the BL1 MDAMB-468 where we couldn't detect any basal or induced expression of COX-2. We had previously shown iNOS was associated with elevated tumor expression of IL-8 in ER-negative breast cancer and was inducible by DETA/ NO in TNBC cell lines [14], and that iNOS inhibition decreased TNBC tumor xenograft IL-6 and IL-8 mRNA expression [23]. Conversely we didn't see any significant influence of DETA/NO treatment on IL-6 secretion in any of the cell lines tested. Potentially, the induction of
IL-6 by NO, maybe dependent on other factors present in the tumor microenvironment but absent in an in vitro setting. We did however find that DETA/NO induced IL-8 secretion in both basal-like cell lines and similar to ERK phosphorylation, IL-8 induction in the BL2 HCC1806 was dependent on EGFR signaling.

Both IL-1 $\beta$ and TNF $\alpha$ are present in the tumor microenvironment. While in acute doses they can have cytotoxic effects [48], when present chronically, they have a strong pro-tumoral effect [49-51]. While increased NO levels didn't effect IL-1 $\beta$ or TNF $\alpha$ in MCF-10A or MDA-MB-468 cells, in the BL2 HCC1806, the activation of the EGFR pathway by NO significantly increased IL-1 $\beta$ and TNF $\alpha$ release, accompanied by TNF $\alpha$ dependent NF$\kappa \mathrm{B}$ activation. NF- $\kappa \mathrm{B}$ regulates the expression of genes involved in key cellular processes such as adhesion, cell cycle, or apoptosis $[52,53]$. These results highlights the cross-talk between EGFR signaling and inflammation processes that are critical in tumor metastasis in BL2 TNBC. The pro-inflammatory cytokine IL- 8 has been previously shown to induce increased cancer stem cell renewal, cell invasion and metastasis and epithelial to mesenchymal transition [14, 54], and we now show a novel mechanism that that links high NO levels to EGFRdependent IL-8 induction in BL2 cells.

As mentioned above, ERK activation is associated with increased migration and invasion [42]. Expression levels and activity of the MMPs are finely regulated during the tumor metastasis. We report DETA/NO increased expression of MMP1 and MMP9 mRNA and increased MMP9 enzymatic activity in the BL2 HCC1806, in an EGFR-dependent manner. Cell migration and invasion were regulated by NO through the EGFR/MAPK pathway, with NO significantly increasing cell migration in both TNBC cells, and in contrast inhibiting migration and invasion of normal MCF-10As. As we can't fully explain why the MCF-10A show reduced migration in the absence of a negative effect on MMP or IL-8 activity, further studies are needed to understand the biphasic effects of $\mathrm{NO}$ in tumoral versus non-tumoral breast cells. Additionally MCF-10A have their limitations as a normal control cell line, due to their immortalized status, however we believe that they are the best available control basal cell line, as primary mammary epithelial cells are ER positive. Indeed the MCF-10A exhibit higher rates of cell migration than either TNBC cell line, which reflects previous reports that they have greater colony formation potential than MDAMB-468 or HCC1806 [55]. Similarly invasion through gelatin (MMP9 substrate) or collagen (MMP1 substrate) matrices was enhanced by DETA/NO, in BL2 but not in BL1 cells, reflecting results observed regarding MMPs expression and activity. However it should be noted that additional and/or more relevant mediators such as uPA/ PAI-1 [56] or cathepsins [56, 57], may play a key role in the observed effects. These effects were totally or at least partially reverted when we combined the NO 
donor with the EGFR or MAPK inhibitors highlighting the importance of the EGFR/MAPK pathway regulating tumor progression in a pro-inflammatory environment.

To summarize, we examined the effect of high levels of NO in three different triple negative, basal like cell lines. Our data indicates that iNOS is a predictor of poor outcome in TNBC patients and particularly in basallike patients. In deciphering the potential mechanism of action, we used the MCF-10A as a non-tumorigenic control cell line, and the MDA-MB-468 and the HCC1806 as representative examples of the BL1 and BL2 subtypes, and found the effects of DETA/NO to be more pronounced on the BL2 cell line. Lehman et al found that, while not statistically significant, patients with BL2 had a worse outcome than BL1 patients. We find that, in response to high levels of NO, the BL2 cell line (HCC1806) shows induction of pro-inflammatory signaling, NF- $\mathrm{B}$ dependent gene-expression, increased migration and invasion which is dependent on EGFR signaling, an intrinsic feature of the BL2 subtype. In this way, high iNOS expression in the tumor samples may contribute to the poor outcome observed in basal-like breast cancer patients by enhanced pro-tumorigenic signaling in the BL2 subtype.

Despite EGFR being highly expressed in a large proportion of TNBC patients, the employment of engineered monoclonal antibodies (mABs) against EGFR is not approved for the treatment of breast cancer, while it is approved for other types of cancer such as colorectal cancer. In recent years, many research groups have pointed to the necessity of reconsidering this approach in TNBC, given the lack of an effective treatment [58-60]. As a consequence, two phase II clinical trials were developed, reporting non-statistically significant differences when combining conventional chemotherapeutic agents with EGFR inhibitor $[61,62]$. However, no patient selection criteria were included in these trials, and considering the heterogeneity of the TNBC subtype this could be something to take into consideration delving in the need of stratifying TNBCs for future trials [63]. In this work, we aimed to shed light on the stratification of the TNBC. We provide substantial clinical and in vitro data showing that basal-like TNBC with high levels of expression of iNOS may be candidates for EGFR targeted therapeutics.

\section{MATERIALS AND METHODS}

\section{Tissue collection and construction of tissue microarray}

Paraffin-embedded $(\mathrm{n}=209)$ tumor specimens were obtained from breast cancer patients diagnosed with TNBC (confirmed ER/PR/HER2 negative) at Galway University Hospitals between 1999-2016. Areas of tumor were identified by the pathologist and tissue microarray constructed. Clinical and pathological information were obtained from medical oncology and pathology reports. Disease staging was performed according to the tumornode-metastasis (TNM) system of the American Joint Committee on Cancer/Union Internationale Contre le Cancer (AJCC/UICC). The Nottingham system was used to determine tumor grade. The collection of tumor specimens, and clinical and pathological information was reviewed and approved by the Galway University Hospitals Ethics Committee (Approval \#CA1012). Recurrence free survival was defined as no recurrence at the local site (breast), regional (lymph nodes) or at distant sites. Metastasis free survival was defined as no metastasis to distant sites. Patients who had distant metastasis at diagnosis were excluded from recurrence free survival and metastasis free survival analysis. Breast cancer specific survival was defined as a cause of death due to breast cancer, and excluded death from other causes (non-breast cancer related).

\section{Immunohistochemistry}

IHC was performed as previously described [64]. Briefly, protein expression in the TNBC samples was evaluated using a 1:200 dilution of mouse-monoclonal (clone 4E5) iNOS Antibody (MA5-17139 Invitrogen). The intensity of the staining received a score of $0-3$ if the staining was negative, weak, moderate, or strong. The TMAs were scored by two pathologist and consensus reached.

\section{Cell culture}

All the cell lines were purchased from the ATCC in 2014 (LGC Standards Ltd, Teddington, UK) and maintained at $37^{\circ} \mathrm{C}$ in a fully humidified $5 \% \mathrm{CO} 2$ atmosphere. All cells were frozen down within 3 passages of receipt and subsequently used within a maximum of 10 passages. MCF$10 \mathrm{~A}$ was grown in Dulbecco's Modified Eagle's Medium/ Nutrient F-12 Ham (DMEM:F12) with 15mM HEPES buffer, $5 \%$ horse serum, EGF $(10 \mu \mathrm{g} / \mathrm{mL})$, hydrocortisone $(0.5 \mu \mathrm{g} / \mathrm{mL})$, insulin $(10 \mu \mathrm{g} / \mathrm{mL})$, cholera toxin $(0.1 \mu \mathrm{g} / \mathrm{mL})$, penicillin (100 units $/ \mathrm{mL})$ and streptomycin $(0.1 \mathrm{mg} / \mathrm{mL})$. MDA-MB-468 and HCC1806 were grown in RPMI-1640 with $10 \%$ fetal bovine serum and penicillin $(100 \mathrm{IU} / \mathrm{mL})$ and streptomycin $(0.1 \mathrm{mg} / \mathrm{mL})$. For experimental purposes, the cells were serum starved in RPMI-1640 media 4 hours before being treated. All the inhibitors employed for this study and their correspondent vehicles, PD153035 (100nM), PD198306 $(200 \mathrm{nM})$, Infliximab $(5 \mu \mathrm{g} / \mathrm{ml})$ or $0.01 \%$ DMSO were administered, 60 minutes before treatment with $50 \mu \mathrm{M} \mathrm{NaOH}$ (vehicle) or 0.1/0.3/0.5mM DETA/NO (Diethylenetriamine/ nitric oxide adduct). Cells were rinsed twice with cold PBS and lysed directly on the dish with cold RIPA buffer (Sigma) supplemented with protease and phosphatases inhibitors, scraped, and spun at $14,000 \mathrm{~g}$ for 15 minutes at $4^{\circ} \mathrm{C}$. Supernatant was collected and stored at $-20^{\circ} \mathrm{C}$ for Western blot analysis of protein expression. 


\section{Constructs and transfection techniques}

The NF-кB Luciferase reporters driven by $5 \mathrm{X}$ wild type (5X NF-кB-Luc) (рNF-кB-Luc plasmid, Stratagene, Santa Clara, CA, USA) or negative control (no NF-кB binding sites-Luc) (pCIS-CK, Stratagene) were used in this study. MCF-10A, MDA-MB-468 and HCC1806 cell lines were plated in 6-well plates and transfected with $1 \mu \mathrm{g}$ of appropriate plasmid using Lipofectamine-LTX reagent (Thermo-Fisher) according to the manufacturer's instructions. Twenty-four hours post transfection, cells were treated with Infliximab for 1 hour followed by $50 \mu \mathrm{M} \mathrm{NaOH}$ or $0.5 \mathrm{mM}$ DETA/NO. Twenty-four hours post treatment, cells were lysed and analyzed for luciferase activity.

\section{Western blot analysis}

Protein concentrations were determined with the Bio-Rad Protein Assay. Western blot analysis was performed according to standard procedures, and $30-50 \mu \mathrm{g}$ of total protein was loaded per lane. The protein bands were visualized using the Super-Signal West Pico Chemiluminescent Substrate (Pierce). The following antibodies were used to detect proteins of interest: rabbitpolyclonal Phospho-EGF Receptor Y1068 (2234), rabbit-polyclonal Phospho-EGF Receptor Y1045 (2237), rabbit-monoclonal Phospho-EGF Receptor Y1173 (4407), mouse-monoclonal EGF Receptor (2239), rabbit-monoclonal Phospho-Erk1/2 T202/Y204 (4370), rabbit-monoclonal Erk1/2 (4695) all from Cell Signaling Technology, rabbitmonoclonal COX-2 (Thermo-Scientific. \#RM-9121-S0) and mouse-monoclonal $\beta$-Actin (Sigma-Aldrich, A5441).

\section{Cytokine quantification}

After treatment, cell culture supernatants were collected for cytokine quantification and spun at $180 \mathrm{~g}$ for 5 minutes to remove debris, and stored at $-80^{\circ} \mathrm{C}$. These supernatants were analyzed with the Meso Scale Discovery (MSD) Human ProInflammatory Panel II (4Plex) Tissue Culture Kit (K15025B). 25ul of sample per well were used to quantify the presence of IL-1 $\beta$, IL-6, IL-8 and TNF $\alpha$.

\section{Gelatin zymography}

Activity MMP-2 and MMP-9 was measured by gelatin zymography. Briefly, the cell lines were seeded in $100 \mathrm{~mm}$ petri dishes and treated with drugs in $10 \mathrm{ml}$ volume. After 24 hours the supernatants were collected and concentrated using Amicon Ultra-4 Centrifugal Filter Unit with Ultracel-30 membrane (Merck Millipore, UFC803024). Samples were electrophoresed on a $8 \%$ SDS-PAGE gel containing $0.2 \%$ gelatin. The gels were washed in $2.5 \%$ Triton X-100 three times and incubated overnight (20 mM TRIS, $5 \mathrm{mM} \mathrm{CaCl} 2, \mathrm{pH} 7.4$ ) at $37^{\circ} \mathrm{C}$.
After staining with Commassie blue and destaining with a methanol/acetic acid mixture, gelatinolytic activity was identified as white bands over a blue background.

\section{Detection of matrix metalloproteinases gene expression}

RT- PCR was performed as previously described [65]. The following primers were used: 5'AAAGGGAATAAGTACTGGGC-3' MMP1 forward; 5'CAGTGTTTTCCTCAGAAAGAG-3' MMP1 reverse; 5'-GTGATCTTGACCAGAATACC-3' MMP2 forward; 5'GCCAATGATCCTGTATGTG-3' MMP2 reverse; 5'AAGGATGGGAAGTACTGG-3' MMP9 forward; 5'-GCCCAGAGAAGAAGAAAAG -3' MMP9 reverse; 5'-AGAGCTACGAGCTGCCTGAC-3' $\beta$-actin forward; 5'AGCACTGTGTTGGCGTACAG-3' $\beta$-actin reverse. Thermal cycling $95^{\circ} \mathrm{C}$ for $2 \mathrm{~min}$, followed by 40 cycles of $95^{\circ} \mathrm{C}$ for $5 \mathrm{~s}$ and $60^{\circ} \mathrm{C}$ for $15 \mathrm{~s}$. Gene expression levels were calculated using the delta $\mathrm{Ct}$ method.

\section{Invasion and motility assays}

Cells were harvested and resuspended in RPMI 1640 containing $5 \%$ of FBS at a concentration of $1 \times 10^{6} \mathrm{cells} / \mathrm{ml}$. $100 \mu 1$ of the cell suspension and 100ul of DETA/NO and PD153035 or PD198306 at the appropriated concentrations were added to $8.0 \mu \mathrm{m}$ pore size inserts (Falcon), in a 24well plate containing $0.5 \mathrm{ml}$ of RMPI1640 supplemented with $10 \%$ FBS. For the invasion assays, the inserts were previously coated with $1 \mathrm{mg} / \mathrm{ml}$ of rat tail collagen (C7661 Sigma-Aldrich), or $0.2 \%$ of porcine skin gelatin (G1890 Sigma-Aldrich). Cells were incubated at $37^{\circ} \mathrm{C}$ for 24 hours for motility assays and 48 hours for invasion assays. After this time, the inner side of the insert was wiped with a wet cotton swab to remove the cells, while the outer side of the insert was gently rinsed with PBS and stained with $0.25 \%$ crystal violet for 5 minutes, rinsed again, and then allowed to dry. The inserts were then viewed under the microscope and the cells over a total of 5 random fields were counted at $\times 200$ magnification, to determine the relative number of invading/migrating cells.

\section{Statistical analysis}

Data analysis was performed using the Stata/SE 14 (Stata Corp, College Station, TX) and GraphPad Prism 5 (GraphPad Software, San Diego, CA) statistical software packages. All statistical tests were twosided. $\mathrm{P}<0.05$ was considered statistically significant. Survival was determined for the period from the date of hospital admission to the date of the last completed search for death entries on the Hospital system. Median and mean follow-up times for breast cancer survival were 46 months and 57 months, respectively (range: 1 to 186 months). A total of 58 of 209 patients died 
during this period. 9 patients who died of other causes were excluded from breast cancer specific survival. Kaplan-Meier curves and log-rank test for equality of the survival function was used for univariate survival analysis. Cell culture experimental data are represented as the mean \pm SEM of three independent biological replicates. Two-way ANOVA and Bonferroni tests were performed.

\section{Abbreviations}

BL1 - basal-like

BL2 - basal-like 2

COX-2 cyclooxygenase-2

DETA/NO - Diethylenetriamine/nitric oxide adduct EGFR - epidermal growth factor receptor

ER - estrogen receptors

IL - interleukin

iNOS - inducible nitric oxide synthase

LAR - luminal androgen receptor

MMP - matrix metalloproteinase

NF-кB - Nuclear factor-kappa B

$\mathrm{NO}$ - nitric oxide

PGE2 - prostaglandin E2

PR - progesterone receptors

RTK - receptor tyrosine kinases

TNBC - triple negative breast cancer

$\mathrm{TNF} \alpha$ - tumor necrosis factor alpha

\section{Author contributions}

Pablo Garrido, Aideen E. Ryan, Sharon A. Glynn designed the study, performed the laboratory experiments and wrote the manuscript.

Aliaa Shalaby and Grace Callagy examined and scored the histopathology and immunohistochemistry.

Elaine M. Walsh, Aliaa Shalaby and Maccon Keane identified and collected all clinical and pathological data on the TNBC patients.

Nessa Keane and Mark Webber constructed the tissue microarrays and performed the immunohistochemistry.

Grace Callagy, Francis J Sullivan and Michael J. Kerin provided access to clinical specimens and gave clinical advice.

Sharon A. Glynn conceived the concept and performed the epidemiological analysis and led the study.

\section{ACKNOWLEDGMENTS}

We thank Dr. Stefan Ambs and Dr. David Wink, National Cancer Institute, Maryland, for their advice during the course of this study.

\section{CONFLICTS OF INTEREST}

Authors declare no conflicts of interest.

\section{FUNDING}

This work was funded by Breast Cancer Now (2013MayPR019) awarded to Sharon Glynn. Pablo Garrido was funded by a Clarin-Marie Curie COFUND Postdoctoral Grants by the Principality of Asturias and the FICYT. Sharon A. Glynn and Aideen E Ryan are also recipients of Irish Cancer Society grants.

\section{REFERENCES}

1. Carey LA, Dees EC, Sawyer L, Gatti L, Moore DT, Collichio F, Ollila DW, Sartor CI, Graham ML, Perou CM. The triple negative paradox: primary tumor chemosensitivity of breast cancer subtypes. Clin Cancer Res. 2007; 13:2329-2334.

2. Dent R, Trudeau M, Pritchard KI, Hanna WM, Kahn HK, Sawka CA, Lickley LA, Rawlinson E, Sun P, Narod SA. Triple-negative breast cancer: clinical features and patterns of recurrence. Clin Cancer Res. 2007; 13:4429-4434.

3. Tischkowitz M, Brunet JS, Begin LR, Huntsman DG, Cheang MC, Akslen LA, Nielsen TO, Foulkes WD. Use of immunohistochemical markers can refine prognosis in triple negative breast cancer. BMC Cancer. 2007; 7:134.

4. Lehmann BD, Bauer JA, Chen X, Sanders ME, Chakravarthy AB, Shyr Y, Pietenpol JA. Identification of human triple-negative breast cancer subtypes and preclinical models for selection of targeted therapies. J Clin Invest. 2011; 121:2750-2767.

5. Burstein MD, Tsimelzon A, Poage GM, Covington KR, Contreras A, Fuqua SA, Savage MI, Osborne CK, Hilsenbeck SG, Chang JC, Mills GB, Lau CC, Brown PH. Comprehensive genomic analysis identifies novel subtypes and targets of triple-negative breast cancer. Clin Cancer Res. 2015; 21:1688-1698.

6. Lehmann BD, Jovanovic B, Chen X, Estrada MV, Johnson KN, Shyr Y, Moses HL, Sanders ME, Pietenpol JA. Refinement of Triple-Negative Breast Cancer Molecular Subtypes: Implications for Neoadjuvant Chemotherapy Selection. PLoS One. 2016; 11:e0157368.

7. Burke AJ, Sullivan FJ, Giles FJ, Glynn SA. The yin and yang of nitric oxide in cancer progression. Carcinogenesis. 2013; 34:503-512.

8. Ambs S, Glynn SA. Candidate pathways linking inducible nitric oxide synthase to a basal-like transcription pattern and tumor progression in human breast cancer. Cell Cycle. 2011; 10:619-624.

9. Switzer CH, Glynn SA, Cheng RY, Ridnour LA, Green JE, Ambs S, Wink DA. S-nitrosylation of EGFR and Src activates an oncogenic signaling network in human basallike breast cancer. Mol Cancer Res. 2012; 10:1203-1215.

10. Wink DA, Vodovotz Y, Laval J, Laval F, Dewhirst MW, Mitchell JB. The multifaceted roles of nitric oxide in cancer. Carcinogenesis. 1998; 19:711-721. 
11. Pervin S, Singh R, Hernandez E, Wu G, Chaudhuri G. Nitric oxide in physiologic concentrations targets the translational machinery to increase the proliferation of human breast cancer cells: involvement of mammalian target of rapamycin/eIF4E pathway. Cancer Res. 2007; 67:289-299.

12. Shami PJ, Sauls DL, Weinberg JB. Schedule and concentration-dependent induction of apoptosis in leukemia cells by nitric oxide. Leukemia. 1998; 12:1461-1466.

13. Nathan C, Xie QW. Nitric oxide synthases: roles, tolls, and controls. Cell. 1994; 78:915-918.

14. Glynn SA, Boersma BJ, Dorsey TH, Yi M, Yfantis HG, Ridnour LA, Martin DN, Switzer CH, Hudson RS, Wink DA, Lee DH, Stephens RM, Ambs S. Increased NOS2 predicts poor survival in estrogen receptor-negative breast cancer patients. J Clin Invest. 2010; 120:3843-3854.

15. Krishnamurti U, Wetherilt CS, Yang J, Peng L, Li X. Tumor-infiltrating lymphocytes are significantly associated with better overall survival and disease-free survival in triple negative but not estrogen receptor positive breast cancers. Hum Pathol. 2017; 64:7-12.

16. Bellizzi A, Greco MR, Rubino R, Paradiso A, Forciniti S, Zeeberg K, Cardone RA, Reshkin SJ. The scaffolding protein NHERF1 sensitizes EGFR-dependent tumor growth, motility and invadopodia function to gefitinib treatment in breast cancer cells. Int J Oncol. 2015; 46:1214-1224.

17. Park HS, Jang MH, Kim EJ, Kim HJ, Lee HJ, Kim YJ, Kim JH, Kang E, Kim SW, Kim IA, Park SY. High EGFR gene copy number predicts poor outcome in triple-negative breast cancer. Mod Pathol. 2014; 27:1212-1222.

18. Thomas DD, Ridnour LA, Isenberg JS, Flores-Santana W, Switzer CH, Donzelli S, Hussain P, Vecoli C, Paolocci N, Ambs S, Colton CA, Harris CC, Roberts DD, et al. The chemical biology of nitric oxide: implications in cellular signaling. Free Radic Biol Med. 2008; 45:18-31.

19. Wink DA, Hines HB, Cheng RY, Switzer CH, FloresSantana W, Vitek MP, Ridnour LA, Colton CA. Nitric oxide and redox mechanisms in the immune response. J Leukoc Biol. 2011; 89:873-891.

20. Thippeswamy T, McKay JS, Morris R, Quinn J, Wong LF, Murphy D. Glial-mediated neuroprotection: evidence for the protective role of the NO-cGMP pathway via neuronglial communication in the peripheral nervous system. Glia. 2005; 49:197-210.

21. Nyati MK, Morgan MA, Feng FY, Lawrence TS. Integration of EGFR inhibitors with radiochemotherapy. Nat Rev Cancer. 2006; 6:876-885.

22. Ripple MO, Kim N, Springett R. Acute mitochondrial inhibition by mitogen-activated protein kinase/extracellular signal-regulated kinase kinase (MEK) 1/2 inhibitors regulates proliferation. J Biol Chem. 2013; 288:2933-2940.

23. Heinecke JL, Ridnour LA, Cheng RY, Switzer CH, Lizardo MM, Khanna C, Glynn SA, Hussain SP, Young HA, Ambs
S, Wink DA. Tumor microenvironment-based feed-forward regulation of NOS2 in breast cancer progression. Proc Natl Acad Sci U S A. 2014; 111:6323-6328.

24. Basudhar D, Somasundaram V, de Oliveira GA, Kesarwala A, Heinecke JL, Cheng RY, Glynn SA, Ambs S, Wink DA, Ridnour LA. Nitric Oxide Synthase-2-Derived Nitric Oxide Drives Multiple Pathways of Breast Cancer Progression. Antioxid Redox Signal. 2016; 26:1044-1058.

25. Glynn SA, Prueitt RL, Ridnour LA, Boersma BJ, Dorsey TM, Wink DA, Goodman JE, Yfantis HG, Lee DH, Ambs S. COX-2 activation is associated with Akt phosphorylation and poor survival in ER-negative, HER2-positive breast cancer. BMC Cancer. 2010; 10:626.

26. Attiga FA, Fernandez PM, Weeraratna AT, Manyak MJ, Patierno SR. Inhibitors of prostaglandin synthesis inhibit human prostate tumor cell invasiveness and reduce the release of matrix metalloproteinases. Cancer Res. 2000; 60:4629-4637.

27. Grosch S, Maier TJ, Schiffmann S, Geisslinger G. Cyclooxygenase-2 (COX-2)-independent anticarcinogenic effects of selective COX-2 inhibitors. J Natl Cancer Inst. 2006; 98:736-747.

28. Balkwill F, Mantovani A. Inflammation and cancer: back to Virchow? Lancet. 2001; 357:539-545.

29. Grellner W, Georg T, Wilske J. Quantitative analysis of proinflammatory cytokines (IL-1beta, IL-6, TNF-alpha) in human skin wounds. Forensic Sci Int. 2000; 113:251-264.

30. Zidi I, Mestiri S, Bartegi A, Amor NB. TNF-alpha and its inhibitors in cancer. Med Oncol. 2010; 27:185-198.

31. Yeung F, Hoberg JE, Ramsey CS, Keller MD, Jones DR, Frye RA, Mayo MW. Modulation of NF-kappaB-dependent transcription and cell survival by the SIRT1 deacetylase. EMBO J. 2004; 23:2369-2380.

32. Wu Y, Zhou BP. Inflammation: a driving force speeds cancer metastasis. Cell Cycle. 2009; 8:3267-3273.

33. Coffelt SB, de Visser KE. Cancer: Inflammation lights the way to metastasis. Nature. 2014; 507:48-49.

34. Jovanovic M, Stefanoska I, Radojcic L, Vicovac L. Interleukin-8 (CXCL8) stimulates trophoblast cell migration and invasion by increasing levels of matrix metalloproteinase (MMP)2 and MMP9 and integrins alpha5 and beta1. Reproduction. 2010; 139:789-798.

35. Liu CJ, Kuo FC, Wang CL, Kuo CH, Wang SS, Chen CY, Huang YB, Cheng KH, Yokoyama KK, Chen CL, Lu CY, Wu DC. Suppression of IL-8-Src signalling axis by 17betaestradiol inhibits human mesenchymal stem cells-mediated gastric cancer invasion. J Cell Mol Med. 2016; 20:962-972.

36. Chambers AF, Groom AC, MacDonald IC. Dissemination and growth of cancer cells in metastatic sites. Nat Rev Cancer. 2002; 2:563-572.

37. Friedl $\mathrm{P}$, Wolf $\mathrm{K}$. Tumour-cell invasion and migration: diversity and escape mechanisms. Nat Rev Cancer. 2003; 3:362-374. 
38. Saha P, Nanda R. Concepts and targets in triple-negative breast cancer: recent results and clinical implications. Ther Adv Med Oncol. 2016; 8:351-359.

39. Granados-Principal S, Liu Y, Guevara ML, Blanco E, Choi DS, Qian W, Patel T, Rodriguez AA, Cusimano J, Weiss HL, Zhao H, Landis MD, Dave B, et al. Inhibition of iNOS as a novel effective targeted therapy against triple-negative breast cancer. Breast Cancer Res. 2015; 17:25.

40. Bos M, Mendelsohn J, Kim YM, Albanell J, Fry DW, Baselga J. PD153035, a tyrosine kinase inhibitor, prevents epidermal growth factor receptor activation and inhibits growth of cancer cells in a receptor number-dependent manner. Clin Cancer Res. 1997; 3:2099-2106.

41. Bartholomeusz C, Gonzalez-Angulo AM, Liu P, Hayashi N, Lluch A, Ferrer-Lozano J, Hortobagyi GN. High ERK protein expression levels correlate with shorter survival in triple-negative breast cancer patients. Oncologist. 2012; 17:766-774.

42. Kim S, Lee J, Jeon M, Lee JE, Nam SJ. MEK-dependent IL-8 induction regulates the invasiveness of triple-negative breast cancer cells. Tumour Biol. 2016; 37:4991-4999.

43. Bartholomeusz C, Xie X, Pitner MK, Kondo K, Dadbin A, Lee J, Saso H, Smith PD, Dalby KN, Ueno NT. MEK Inhibitor Selumetinib (AZD6244; ARRY-142886) Prevents Lung Metastasis in a Triple-Negative Breast Cancer Xenograft Model. Mol Cancer Ther. 2015; 14:2773-2781.

44. Gupta S, Srivastava M, Ahmad N, Bostwick DG, Mukhtar H. Over-expression of cyclooxygenase-2 in human prostate adenocarcinoma. Prostate. 2000; 42:73-78.

45. Rubio J, Ramos D, Lopez-Guerrero JA, Iborra I, Collado A, Solsona E, Almenar S, Llombart-Bosch A. Immunohistochemical expression of Ki-67 antigen, cox-2 and $\mathrm{Bax} / \mathrm{Bcl}-2$ in prostate cancer; prognostic value in biopsies and radical prostatectomy specimens. Eur Urol. 2005; 48:745-751.

46. Tsujii M, Kawano S, Tsuji S, Sawaoka H, Hori M, DuBois RN. Cyclooxygenase regulates angiogenesis induced by colon cancer cells. Cell. 1998; 93:705-716.

47. Brown JR, DuBois RN. COX-2: a molecular target for colorectal cancer prevention. J Clin Oncol. 2005; 23:2840-2855.

48. Mantovani A, Bonecchi R, Locati M. Tuning inflammation and immunity by chemokine sequestration: decoys and more. Nat Rev Immunol. 2006; 6:907-918.

49. Kaler P, Augenlicht L, Klampfer L. Macrophage-derived IL-1beta stimulates Wnt signaling and growth of colon cancer cells: a crosstalk interrupted by vitamin D3. Oncogene. 2009; 28:3892-3902.

50. Balkwill F. Tumour necrosis factor and cancer. Nat Rev Cancer. 2009; 9:361-371.

51. Ben-Baruch A. The Tumor-Promoting Flow of Cells Into, Within and Out of the Tumor Site: Regulation by the
Inflammatory Axis of TNFalpha and Chemokines. Cancer Microenviron. 2012; 5:151-164.

52. Karin M, Lin A. NF-kappaB at the crossroads of life and death. Nat Immunol. 2002; 3:221-227.

53. Karin M, Cao Y, Greten FR, Li ZW. NF-kappaB in cancer: from innocent bystander to major culprit. Nat Rev Cancer. 2002; 2:301-310.

54. Fernando RI, Castillo MD, Litzinger M, Hamilton DH, Palena C. IL-8 signaling plays a critical role in the epithelial-mesenchymal transition of human carcinoma cells. Cancer Res. 2011; 71:5296-5306.

55. Shemesh CS, Hardy CW, Yu DS, Fernandez B, Zhang H. Indocyanine green loaded liposome nanocarriers for photodynamic therapy using human triple negative breast cancer cells. Photodiagnosis Photodyn Ther. 2014; 11:193-203.

56. Huber MC, Mall R, Braselmann H, Feuchtinger A, Molatore S, Lindner K, Walch A, Gross E, Schmitt M, Falkenberg N, Aubele M. uPAR enhances malignant potential of triplenegative breast cancer by directly interacting with uPA and IGF1R. BMC Cancer. 2016; 16:615.

57. Anantaraju HS, Battu MB, Viswanadha S, Sriram D, Yogeeswari P. Cathepsin D inhibitors as potential therapeutics for breast cancer treatment: Molecular docking and bioevaluation against triple-negative and triple-positive breast cancers. Mol Divers. 2016; 20:521-535.

58. Ingthorsson S, Andersen K, Hilmarsdottir B, Maelandsmo GM, Magnusson MK, Gudjonsson T. HER2 induced EMT and tumorigenicity in breast epithelial progenitor cells is inhibited by coexpression of EGFR. Oncogene. 2016; 35:4244-4255.

59. Ferraro DA, Gaborit N, Maron R, Cohen-Dvashi H, Porat Z, Pareja F, Lavi S, Lindzen M, Ben-Chetrit N, Sela M, Yarden Y. Inhibition of triple-negative breast cancer models by combinations of antibodies to EGFR. Proc Natl Acad Sci U S A. 2013; 110:1815-1820.

60. Nabholtz JM, Chalabi N, Radosevic-Robin N, Dauplat MM, Mouret-Reynier MA, Van Praagh I, Servent V, Jacquin JP, Benmammar KE, Kullab S, Bahadoor MR, Kwiatkowski F, Cayre A, et al. Multicentric neoadjuvant pilot Phase II study of cetuximab combined with docetaxel in operable triple negative breast cancer. Int J Cancer. 2016; 138:2274-2280.

61. Baselga J, Gomez P, Greil R, Braga S, Climent MA, Wardley AM, Kaufman B, Stemmer SM, Pego A, Chan A, Goeminne JC, Graas MP, Kennedy MJ, et al. Randomized phase II study of the anti-epidermal growth factor receptor monoclonal antibody cetuximab with cisplatin versus cisplatin alone in patients with metastatic triple-negative breast cancer. J Clin Oncol. 2013; 31:2586-2592.

62. Carey LA, Rugo HS, Marcom PK, Mayer EL, Esteva FJ, Ma CX, Liu MC, Storniolo AM, Rimawi MF, Forero-Torres A, Wolff AC, Hobday TJ, Ivanova A, et al. TBCRC 001: randomized phase II study of cetuximab in combination 
with carboplatin in stage IV triple-negative breast cancer. J Clin Oncol. 2012; 30:2615-2623.

63. Bianchini G, Balko JM, Mayer IA, Sanders ME, Gianni L. Triple-negative breast cancer: challenges and opportunities of a heterogeneous disease. Nat Rev Clin Oncol. 2016; 13:674-690.

64. Prueitt RL, Boersma BJ, Howe TM, Goodman JE, Thomas DD, Ying L, Pfiester CM, Y fantis HG, Cottrell JR, Lee DH, Remaley AT, Hofseth LJ, Wink DA, et al. Inflammation and IGF-I activate the Akt pathway in breast cancer. Int $\mathrm{J}$ Cancer. 2007; 120:796-805.

65. Wallace TA, Downey RF, Seufert CJ, Schetter A, Dorsey TH, Johnson CA, Goldman R, Loffredo CA, Yan P, Sullivan FJ, Giles FJ, Wang-Johanning F, Ambs S, et al. Elevated HERV-K mRNA expression in PBMC is associated with a prostate cancer diagnosis particularly in older men and smokers. Carcinogenesis. 2014; 35:2074-2083. 